Review Article

\title{
The Effects of Traditional Chinese Medicine-Associated Complementary and Alternative Medicine on Women with Polycystic Ovary Syndrome
}

\author{
Wenjuan Shen $\mathbb{D}^{1},{ }^{1}$ Bao Jin, ${ }^{2}$ Yujia Pan, ${ }^{2}$ Yanhua Han,, ${ }^{1}$ Tianjiao You, ${ }^{2}$ Zongyu Zhang, \\ Yangfan Qu, ${ }^{2}$ Sha Liu, ${ }^{3}$ and Yang Zhang ${ }^{4}{ }^{4}$ \\ ${ }^{1}$ Department of Obstetrics and Gynecology, First Affiliated Hospital, Heilongjiang University of Chinese Medicine, \\ Harbin 150040, China \\ ${ }^{2}$ Department of Obstetrics and Gynecology, Heilongjiang University of Chinese Medicine, Harbin 150040, China \\ ${ }^{3}$ Department of Internal Medicine, Heilongjiang University of Chinese Medicine, Harbin 150040, China \\ ${ }^{4}$ Department of Internal Medicine, First Affiliated Hospital, Heilongjiang University of Chinese Medicine, Harbin 150040, China
}

Correspondence should be addressed to Yang Zhang; yangzhang83@163.com

Received 10 December 2020; Revised 1 February 2021; Accepted 15 February 2021; Published 26 February 2021

Academic Editor: Yong Wang

Copyright $\odot 2021$ Wenjuan Shen et al. This is an open access article distributed under the Creative Commons Attribution License, which permits unrestricted use, distribution, and reproduction in any medium, provided the original work is properly cited.

Polycystic ovary syndrome (PCOS) is a touchy clinical and public health problem worldwide, which adversely affects women's health and health-related comorbidities for lifetime, and represents a tremendous burden for both the family of the patient and for society. According to the diagnostic criteria used and the population studied, the prevalence rate of PCOS is between $6 \%$ and $21 \%$. However, current conventional modern medicines for PCOS are only moderately effective at controlling the signs and symptoms, while they are not thoroughly able to prevent complications. Therefore, many patients have turned to complementary and alternative medical (CAM) treatments. CAM use is wide spread among patients with PCOS, and more than $70 \%$ of patients use CAM at one point during their diseases. The patients' primary motivations include dissatisfaction with available medications, perceive higher risk of drug side effects and crushing health burden and economic costs, desire for symptom relief, pursuit of shortening the course of disease, and the belief that CAM therapy is in accordance with the patients' values and beliefs. At present, several CAM methods have been used in women with PCOS, which has achieved obvious effects. However, biologically plausible mechanisms of the action of traditional Chinese medicine- (TCM-) associated CAM for PCOS have not been systematically reviewed. This review briefly summarizes the current progress of the impact of herbal medicine on the outcomes of PCOS and introduces the mechanisms.

\section{Introduction}

Polycystic ovary syndrome (PCOS) is one of the most common and complex endocrinopathy occurring in reproductive aged women. According to the diagnostic criteria used and the population studied, the prevalence rate of PCOS is between $6 \%$ and $21 \%$ [1]. PCOS is characterized by chronic anovulation, hyperandrogenism (HA), and metabolism disorder leading to symptoms of menstrual dysfunction, subfertility, hirsutism, acne, and obesity [2]. Women with PCOS tend to have other abnormalities, including impaired glucose tolerance, type 2 diabetes mellitus, dyslipidemia, increased prevalence of hypertension, and possibly increased risk of metabolic syndrome and cardiovascular morbidity [3]. The aetiology of PCOS remains poorly understood, but it is believed to result from a complex relationship with metabolic, endocrine, genetic, behavioral, and environmental factors. Different possible theories were reported in various studies, which included detectable insulin resistance (IR), HA, and neuroendocrine gonadotropin secretion disorders, or a combination of these factors [4]. PCOS as a whole is a touchy clinical and public health problem worldwide, which adversely affects women's health and health-related comorbidities lifetime, and represents a 
tremendous burden for both the family of the patient and for society. The annual cost to the National Health Service modelled the population dynamics of PCOS, healthcare costs, and quality of life for PCOS patients in the UK from 2014 to 2039 and has been estimated to be more than $£ 237$ million [5].

About $70 \%$ of people around the worldwide are interested in the prevention and treatment of diseases by complementary and alternative medicine (CAM) although there is insufficient scientific assessment evidence to prove its safety and effectiveness [6]. The National Center for Complementary and Integrative Health (NCCIH), formerly known as the National Center for Complementary and Alternative Medicine (NCCAM), defines CAM as a group of diverse medical and health-care systems, practices, and products that are not presently considered to be part of conventional modern medicine. NCCIH classifies CAM into three more types: (1) natural products (consist of herbs, vitamins, minerals, probiotics, and dietary supplements); (2) mind and body practices (include a wide variety of procedures and techniques such as yoga, acupuncture, Tai chi or qi gong, massage therapy, meditation, spinal manipulation, hypnotherapy, and relaxation techniques), and (3) other complementary health approaches [7] (other complementary health approaches cover those treatments such as traditional Chinese medicine (TCM), naturopathy, and homeopathy as well as functional medicine).

Patients with PCOS rank among the higher users of CAM. Why so many people choose CAM? Their primary motivations include dissatisfaction with available medications, perceive a higher risk of drug side effects and crushing health burden and economic costs, desire for symptom relief, pursuit of shortening the course of disease, and the belief that CAM therapy is in accordance with the patients' values and beliefs. Sometimes, the patients who resort to CAM usually use it as a "alternative" therapy, but there are moments the CAM are used to incorporate with conventional modern medicine on behalf of treating and controlling the primary disease or complications as much as possible to achieve better efficacy. Given the wide application of CAM in women with PCOS, particularly the remarkable efficacy of CAM therapy in clinical randomized controlled trials of PCOS in recent years. The purpose of this narrative review is to provide a broad overview of the types of TCM-associated CAM therapies most commonly be used for PCOS and to enable patients and practitioners who are either interested in pursuing or already employing CAM to know more about the relevant research progress and mechanism.

\section{The Utilization of Herbal Medicine in Women with PCOS}

Herbal medicine (HM) has been used in eastern Asian countries for thousands of years, and it is one of the key components of CAM. One particular form of HM, herbal formula, involves the use of some herbs in a formula to improve a set of problems or a syndrome. Herbal formula and single herb were reportedly used by over $70 \%$ of women with PCOS and are a commonly encountered condition among traditional Chinese doctors [8, 9]. Many studies showed that both herbal formula and single herb are helpful for fertility, menstrual health, and other aspects of PCOS. In view of the use of HM in PCOS are becoming popular in research and clinical practice, we summarized the outcomes of clinical and the mechanisms as follows.

\subsection{The Utilization of Herbal Formula in Women with PCOS}

2.1.1. Infertility and Ovulatory Dysfunction. As the treatment of infertility has attracted much attention from PCOS patients, numerous clinical studies of herbal formula have been designed, especially, quite prevalent in China. Herbal formula had positive adjunct effects with clomiphene citrate (CC) in the management of ovulation induction for PCOSrelated subfertility [10-17]. The results of Chen et al. show that the prevalence of dominant follicle, ovulation rate, and clinical pregnancy rate in the combination group was significantly superior than those in the control group $(P<0.05)$ [18]. Consistent with these data, Zhao et al. also found the same discovery in 120 subjects undergoing inducing ovulation in women with PCOS; there were significantly a higher pregnancy rate $(29.0 \%$ vs $15.6 \%)$ and lower early abortion rate $(12.9 \%$ vs $23.5 \%)$ in the cotreatment group than that in the CC group [19], since CC is a selective estrogen modulator known to negatively impact endometrial development. Previous studies have shown that cotreatment with herbal formula significantly increased the endometrial thickness and pregnant rate for infertility treatment of PCOS $[13,20,21]$. Furthermore, adjuvant treatment of herbal formula also plays a positive role in improving the morphology and reserve capacity of the ovary, particularly ovarian volume and basal antral follicle count (AFC) [22-26]. Ru et al. applied to CC with herbal formula or without herbal formula in 180 PCOS patients and found that endometrial thickness, ovulation function, and clinical pregnancy rate were remarkable improved $(P<0.05)[12]$. Moreover, Danhuang Quyu capsule, Tiangui capsule, and Dingkun pill all have outstanding advantages in improving pregnancy rate and enhancing the sensitivity to ovulationinducing drugs $[13,27]$. Wei et al. carried out a prospective clinical study and reported higher single follicle rate, mature follicle rate, and clinical pregnancy rate among those subjects who received Dingkun pill and CC compared with subjects in the control group (58.0\% vs. $38.0 \%$; $98.0 \%$ vs. $78.0 \% ; 42.0 \%$ vs. $18.0 \% ; P<0.05$ ) [13]. Recently, letrozole has been considered as an alternative to CC and has been used in ovulating and nonovulating infertile women with PCOS, especially for patients who are against CC. With regard to cycle ovulation rate and pregnancy rate, as well as the total effective rate of intervention, the results of the present studies reveal that herbal formula conjunction with letrozole is more effective than letrozole monotherapy in the treatment of PCOS [28, 29]. In a randomized controlled trial (RCT), Yuan et al. evaluated the effectiveness and efficacy of letrozole combined with HM prescription in CC-resistant infertile women with PCOS. The data exerted a significantly 
higher ovulation rate, clinical pregnancy rate, endometrial thickness, and a dramatically regulated hormonal status over 6 treatment cycles in the combination group [14]. In addition, others argue that Chinese herbal formula (CHF) appears to be at least as effective as CC in ovulation induction with some potential advantages over CC [30-32]. Li in a 3-menstrual cycle human study found that $\mathrm{CHF}$ improved pregnancy outcome compared with CC among 120 infertile PCOS patients [30]. In agreement with Li's findings, Zhou et al. also demonstrated the benefits of CHF on ovulation rate and pregnancy rate, ovarian volume, and endometrial thickness [31].

CAM treatments are commonly used as adjunctive therapy for women when they undergo in vitro fertilization (IVF) treatment, and herbal formula is widely chosen. There are positive effects on reproductive outcomes for those PCOS patients undergoing ovulation when adjuvant treatment with $\mathrm{CHF}$ at different time points of IVF treatment $[33,34]$. Zhang et al. randomized 98 cases of PCOS patients who would undergo in vitro fertilization and embryo transfer (IVF-ET) to the CHF group and control group; $\mathrm{CHF}$ group received 3 months treatment with herbal formula before IVF-ET; control group did not receive any treatment before IVF-ET; and the results presented better higher quality embryo rate, implantation rate, and pregnancy rate in the $\mathrm{CHF}$ group than in the control group [33]. Meanwhile, using Cangfu Congxian decoction, before 2 months of IVFET, could significantly increase oocyte retrieval number, high-quality embryos, and $2 \mathrm{PN}$ fertilization rate [34]. Adjuvant drug of CHF could improve patients' sensitivity to medicine of superovulation when the patient received controlled ovarian hyperstimulation [35-37]. The results of Lian confirmed that, in the CHF group, patients took herbal formula until human chorionic gonadotropin (HCG) injection day and achieved a higher increment in the oocytes number and clinical pregnancy rate compared with the placebo group undergoing IVF-ET [37].

Although there are hundreds of positive results referring to herbal formulas for infertility treatment in women with PCOS, there are still negative results. Zhu et al. discovered the negative results in 54 subjects undergoing IVF-ET; they found that treatment with herbal medicine compound could not dramatically increase the numbers of fertilized oocytes, high-quality embryos, and the pregnant chance $(P>0.05)$ [38]. However, some other studies have demonstrated that although herbal formula could not change ovulation rate and pregnancy rate, herbal formula could improve the level of estradiol $\left(\mathrm{E}_{2}\right)$, luteinizing hormone $(\mathrm{LH})$, and testosterone (T) and increase the blood flow of ovary [39, 40]. The possible reasons for these different findings might be concerned with differences in the study design and compound prescription composition.

2.1.2. Hormonal Status and Menstruation Cycle. With the continuous exploration of the treatment of PCOS, herbal formula has been a potential treatment for irregular menstruation and hormonal imbalance in PCOS. A pilot study conducted recently in UK found herbal formula could statistically improve menstrual rates; meanwhile, liver and kidney function and adverse events data were largely normal [17]. Additionally, as HM and Western medicine (WM) have different mechanisms of action, the combination of treatment was more effective in the regulation of menstrual cycle and hormonal status $[15,16,24,41]$. Chen provided that Chinese medicine cycle therapy combined with metformin had beneficial effects for women with oligomenorrhea, amenorrhea, and sex hormone in PCOS [42]. Zhang conducted a randomized controlled prospective study; the results confirmed that the combination group achieved a significant reduction in $\mathrm{T}, \mathrm{LH}$, and $\mathrm{E}_{2}$ levels and the scores for Chinese medical syndromes $(P<0.05)$ [43]. Li and Yuan applied to an adjuvant treatment with $\mathrm{CHF}$ or without $\mathrm{CHF}$ in PCOS patients and found that hormonal serum, antiMullerian hormone (AMH), and Chinese medical syndromes in the adjuvant treatment group were better than those in the control group [44]. However, because the composition of Chinese herbal formulas is different, the influence on the outcomes is not completely the same. The results of Wang Ping supported the fact that, despite no significant difference in serum of $\mathrm{E}_{2}, \mathrm{~T}$, follicle stimulating hormone $(\mathrm{FSH})$, and ovarian volume, $\mathrm{CHF}$ would be clinically useful, especially in patients with $\mathrm{LH}, \mathrm{LH} / \mathrm{FSH}$, and basal AFC disturbances in PCOS [45].

Moreover, herbal formula could cause hormonal changes and modify HA with little sideeffects [46-49]. Liu et al. randomized 120 cases of PCOS-HA women to the CHF group and control group; after 3 months treatment, the results showed significant reduction in $\mathrm{T}$, free androgen index (FAI), dihydrotestosterone (DHT), and dehydroepiandrosterone sulfate (DHEAS) levels and increased the level of sex hormone binding globulin (SHBG) and FSH in the CHF group than in the control group $(P<0.01)$; and $\mathrm{CHF}$ had better effects for modifying Rosenfield and hirsutism $(P<0.01)$, promoting recovery of menstrual and spontaneous ovulation $(P<0.05)[50]$.

Herbal formula can improve reproductive dysfunctions, but at the same time, it has beneficial effects on balancing hormone status and menstrual frequency of PCOS that is also very intriguing $[15,16,41,42,51]$. Susan et al. conducted a RCT of 122 patients; the results found that herbal formula adjuvant group recorded a reduction in oligomenorrhoea and other significant improvements such as pregnancy rates and quality of life compared with controls $(P<0.01)$ in these overweight patients with PCOS [52]. In one trial by Zhang et al., 291 women were identified as PCOS and underwent metformin, Diane-35, or Tiangui capsule. After 3 months intervention, women who received Tiangui capsule had a higher menstrual rate and ovulation rate and lower ovarian volume serum and $\mathrm{T}$ level than the metformin group; the reduction of HA was similar to who received Tiangui capsule or Diane-35. This result was similar to another result that was noted by Huang [53], who used CHF to treat PCOS women. Furthermore, the long-term effect of herbal formula was superior than that of Diane-35 after consecutive 6 months. The hirsute, acne score, and hormonal-related parameters of the herbal formula group were still significantly lower than those of the control group at the end of 6 
months and 3 months of withdrawal $(P<0.05)$, while those in the control group increased.

\subsubsection{Metabolic Dysfunction and Emotional Disturbance.} Some studies showed herbal formula displayed the similar or superior effect on ameliorating glucolipid metabolism alterations compared with WM in women with PCOS [54-56]. A randomized, double-blind, placebo-controlled trial focused on the impact of Kuntai capsule in subjects with PCOS found out a significant decrease in total cholesterol (TC), triglyceride (TG), and low-density lipoprotein level, as well as insulin and homeostasis model assessment of insulin resistance (HOMA-IR) in the CHF group than in the control group, while insulin sensitivity index (ISI) and high-density lipoprotein cholesterol (HDL-C) increased markedly. The results implied that Kuntai capsule resembled an insulin sensitizing agent in therapeutic effect [55]. The study of Wei Feng also showed that CHF was similar to metformin in improving IR [57]. The herbal formula for Bushen Quyu Huatan has marvelous effect on controlling metabolic parameters of PCOS [58, 59]. Cangfu Daotan decoction a classic prescription commonly used for the treatment of PCOS, which is effective in regulating insulin, glucose, and lipid metabolism, has no obvious adverse effects [43, 60-62]. Many studies have reported that herbal formula intensified the metabolic effects of conventional drugs and maybe a newer therapeutic option for the same purpose [26, 63-65]. During Li's study, 126 participants were advised to undergo conventional intervention, or adding HMs, there was significant improving in glycated hemoglobin (HbA1c), fasting insulin (FINS), HOMA-IR, TC, and TG parameters between the combination group and the conventional treatment group [44].

The effects of different herbal formulas on regulating abnormal metabolism are different. Some clinical trials reported controversial findings of diverse herbal formulas treatment about waist hip rate (WHR), body weight (BW) and body mass index (BMI), lipid profiles, and glucose homeostasis parameters of PCOS patients [62-66]. And some studies showed that herbal formulas in PCOS patients led to WHR reduction and BW loss $[27,66]$. Administration of Tiangui capsule, Guizhi Fuling capsule, and Wenjing Shexue recipe led to a substantial decrease in BW, BMI, and other anthropometric indices [27, 39, 53], whereas the findings of Lian were not exactly the same to the above, and Lian found sequential CHF could intensify amelioration in insulin (INS) and ISI level but no changes were observed in fasting blood glucose (FBG) and WHR and BMI outcomes in IR women with PCOS $[67,68]$. Fewer adverse events were found in adjuvant treatments of CHF than that in the conventional treatments $[24,43,60,61]$. The similar discovery was found by $\mathrm{Li}$, they asserted that cotherapy with Bailing capsule could conspicuously regulate metabolic parameters compared with Diane-35 alone, and the cotherapy could protect renal function with no negative effect on liver function [69]. Adjuvant therapy with herbal formula may not only help to ameliorate the glucose and lipid metabolism disorder but also to indirectly improve fertility and hormonal condition in women with PCOS [56, 70-73]. Teng suggested the optional use of herbal formula as an adjuvant therapy for infertility to modify lipid disturbances and then remarkably increase the embryo implantation rate in 227 dyslipidemia women with PCOS undergoing IVF [74].

Furthermore, PCOS is a common endocrine disorder with psychological and emotional disturbance throughout the life course of affected women. Herbal formulas appear to improve symptoms of anxiety, depression, and quality of life in PCOS patients and may enhance the overall effects $[15,75,76]$. Fu conducted a randomized controlled prospective study, which also confirmed this point; the results confirmed that the herbal formula decreased the anxiety and depression scale scores (self-rating anxiety scale and selfrating depression scale) and improved the hormonal status causing considerable alterations in ovulation and pregnancy rate [77]. We have listed some clinical trials in Table 1.

2.1.4. The Mechanism of Herbal Formula Action in Women with PCOS. Regarding the potential mechanisms of herbal formula effect on PCOS, the following points deserve careful consideration. The first point is that herbal formula can be effective to improve IR and glucolipid disorders. Herbal formula improving IR is related to interventions on all fronts of the insulin signaling pathway mainly including insulin receptor, phosphoinositide 3-kinase $(\mathrm{PI} 3 \mathrm{~K})$ /protein kinase $\mathrm{B}$ (Akt), glucose transporter, glycogen synthase kinase 3, mitogen-activated protein kinase (MAPK), and AMP-activated protein kinase (AMPK) as revealed by both in vitro and in vivo studies [37, 43, 44, 78-83]. Considerable herbal formulas, for instance, Cangfu Daotan decoction, Liuwei Dihuang pill, and Heqi san, result in promoted insulin sensitivity through modulation of diverse physiological and cell signaling pathways $[78,80,82]$. The effects of herbal formula are not only confined to boosting insulin sensitivity but also can be beneficial for alleviating lipid abnormality. The previous studies suggested that CHF could significantly change in glycemic index, insulin sensitivity, TG, and HDL$\mathrm{C}$, exerting protective effects against metabolic disorder $[55,64,84,85]$. Visfatin (VF), leptin (LEP), and adiponectin (APN) are closely related to obesity $[86,87]$. The imbalance of adipose cytokines such as LEP and APN secreted by adipose tissue in obese patients will also aggravate the IR of PCOS. Some experts have found that herbal formulas also can decrease serum levels of VF and leptin LEP while increase APN level, improving glucolipid metabolism and wellbeing [71, 88].

The second point is that herbal formula can enhance the endometrial receptivity (ER), which improves fertility. The major target organ of estrogen and progesterone $(\mathrm{P})$ is endometrium. The estrogen and $\mathrm{P}$ supplied by the ovary can facilitate the proliferation and differentiation of endometrial cells, strengthening the ability of endometrium to accept embryos. Studies shown CHF can increase the levels of estrogen and $\mathrm{P}$ and the expressions of their receptors $[13,21,89]$. Endometrial thickness and endometrial morphology are also important parameters affecting the success 
TABLE 1: Summary of randomized studies of the effect of herbal formula on PCOS outcomes.

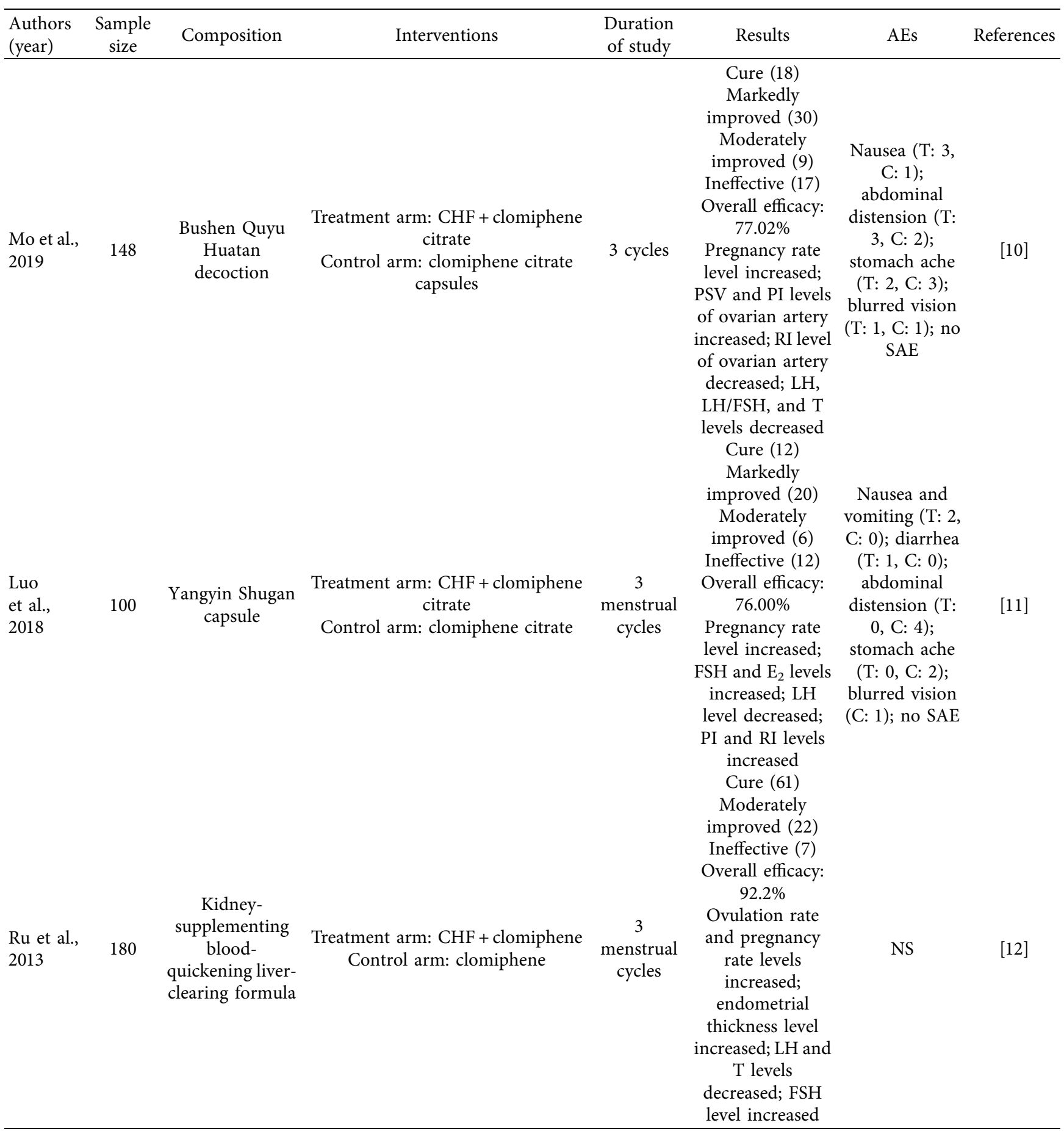


TABle 1: Continued.

\begin{tabular}{|c|c|c|c|c|c|c|c|}
\hline $\begin{array}{l}\text { Authors } \\
\text { (year) }\end{array}$ & $\begin{array}{l}\text { Sample } \\
\text { size }\end{array}$ & Composition & Interventions & $\begin{array}{l}\text { Duration } \\
\text { of study }\end{array}$ & Results & AEs & References \\
\hline $\begin{array}{l}\text { Chen } \\
\text { et al., } \\
2017\end{array}$ & 150 & $\begin{array}{l}\text { Zuogui soothing } \\
\text { liver decoction }\end{array}$ & $\begin{array}{l}\text { Treatment arm: CHF + clomiphene } \\
\text { Control arm: clomiphene }\end{array}$ & 6 months & $\begin{array}{c}\text { Cure (44) } \\
\text { Markedly } \\
\text { improved (3) } \\
\text { Moderately } \\
\text { improved (21) } \\
\text { Ineffective (7) } \\
\text { Overall efficacy: } \\
90.67 \% \\
\text { Ovulation rate, } \\
\text { pregnancy rate, } \\
\text { and dominant } \\
\text { follicular rate } \\
\text { levels increased; } \\
\text { LH, FSH, and T }\end{array}$ & $\begin{array}{l}\text { Intrauterine } \\
\text { membrane } \\
\text { thinning (T: } 6 \text {, } \\
\text { C: } 8 \text { ); OHSS } \\
\text { (T: } 2, \text { C: } 3 \text { ); no } \\
\text { SAE }\end{array}$ & [18] \\
\hline $\begin{array}{l}\text { Ding } \\
\text { et al., } \\
2014\end{array}$ & 355 & $\begin{array}{l}\text { Cangfu Daotan } \\
\text { decoction }\end{array}$ & $\begin{array}{c}\text { Treatment I arm: } \\
\text { clomiphene + HMG + HCG } \\
\text { Treatment II arm: } \\
\text { CHF + clomiphene + HMG + HCG } \\
\text { Control arm: no intervention }\end{array}$ & 3 cycles & $\begin{array}{l}\text { levels decreased } \\
\text { Pregnancy rate } \\
\text { level increased; } \\
\text { endometrial } \\
\text { thickness level } \\
\text { increased; PI and } \\
\text { RI levels } \\
\text { decreased; } \\
\text { HOMA-IR level } \\
\text { decreased; UCP2 } \\
\text { level increased } \\
\text { (treatment II) }\end{array}$ & NS & {$[21]$} \\
\hline $\begin{array}{l}\text { Wang } \\
\text { et al., } \\
2016\end{array}$ & 110 & $\begin{array}{l}\text { Bailing Tiaogan } \\
\text { decoction }\end{array}$ & $\begin{array}{c}\text { Treatment arm: } \\
\mathrm{CHF}+\text { ethinylestradiol cyproterone } \\
\text { acetate + clomiphene } \\
\text { Control arm: ethinylestradiol } \\
\text { cyprogesterone + clomiphene }\end{array}$ & $\begin{array}{c}4 \\
\text { menstrual } \\
\text { cycles }\end{array}$ & $\begin{array}{l}\text { Pregnancy rate } \\
\text { and endometrial } \\
\text { thickness levels } \\
\text { increased; } \\
\text { ovarian volume } \\
\text { level decreased; } \\
\text { TCM symptom } \\
\text { scores level } \\
\text { decreased; FFA } \\
\text { and CRP levels } \\
\text { decreased; } \beta \text {-EP }\end{array}$ & NS & {$[22]$} \\
\hline $\begin{array}{l}\text { Zhang } \\
\text { et al., } \\
2014\end{array}$ & 291 & Tiangui capsule & $\begin{array}{l}\text { A arm: Tiangui capsule } \\
\text { B arm: metformin } \\
\text { C arm: Diane-35 }\end{array}$ & 3 months & $\begin{array}{c}\text { level increased } \\
\text { Markedly } \\
\text { improved (47) } \\
\text { Moderately } \\
\text { improved (35) } \\
\text { Ineffective (28) } \\
\text { Overall efficacy: } \\
\text { 74.55\% } \\
\text { HOMA-IR level } \\
\text { decreased; weight } \\
\text { level decreased; } \\
\text { TC level } \\
\text { decreased; FSH } \\
\text { and T levels } \\
\text { decreased; ovary } \\
\text { volume level } \\
\text { decreased }\end{array}$ & $\begin{array}{l}\text { Mild in B arm: } \\
\text { numbness, } \\
\text { nausea, } \\
\text { diarrhea; mild } \\
\text { in C arm: the } \\
\text { lower limbs are } \\
\text { swollen and } \\
\text { the weight gain } \\
\text { is obvious; no } \\
\text { SAE }\end{array}$ & [27] \\
\hline
\end{tabular}


TABle 1: Continued.

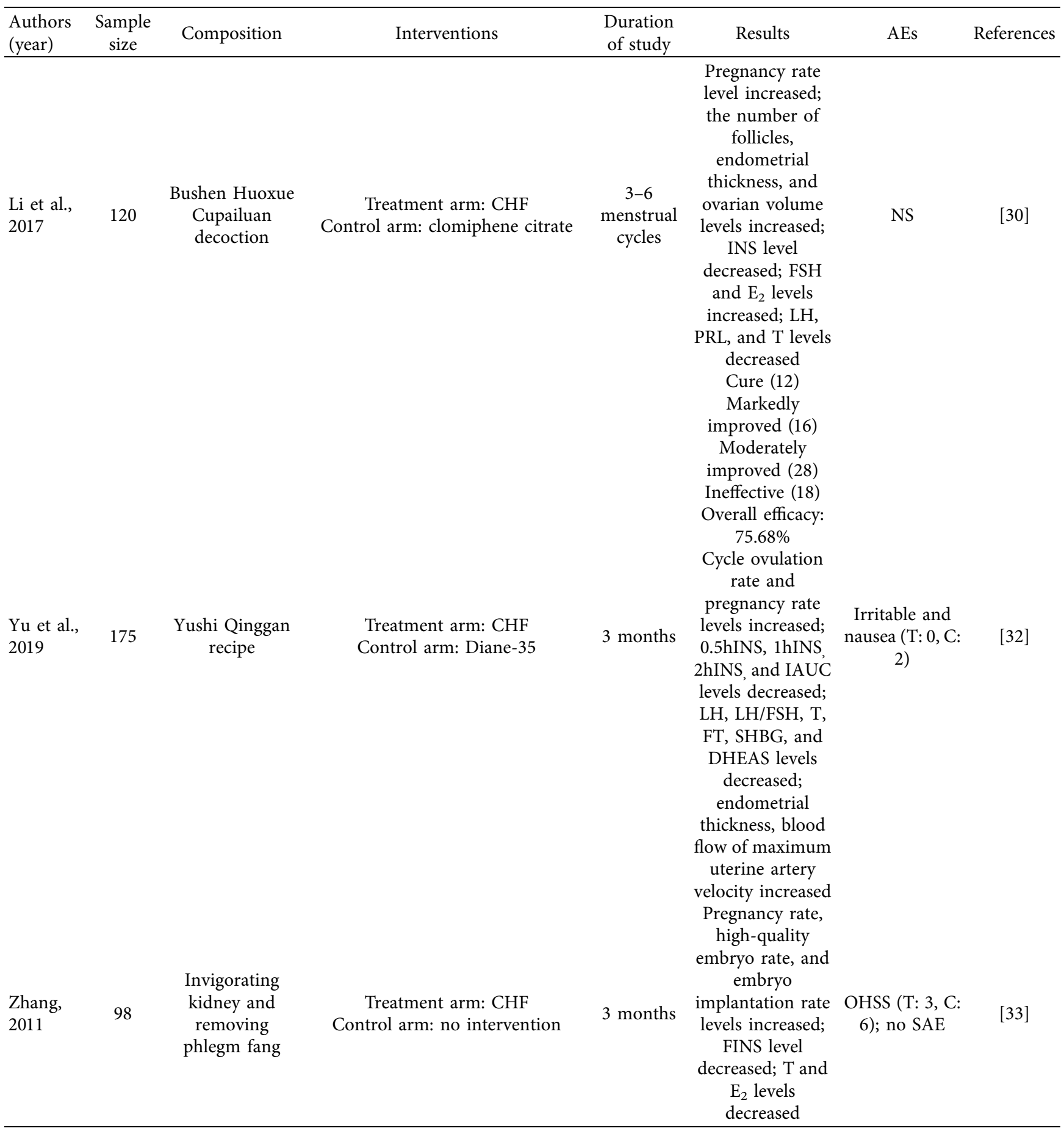


TABle 1: Continued.

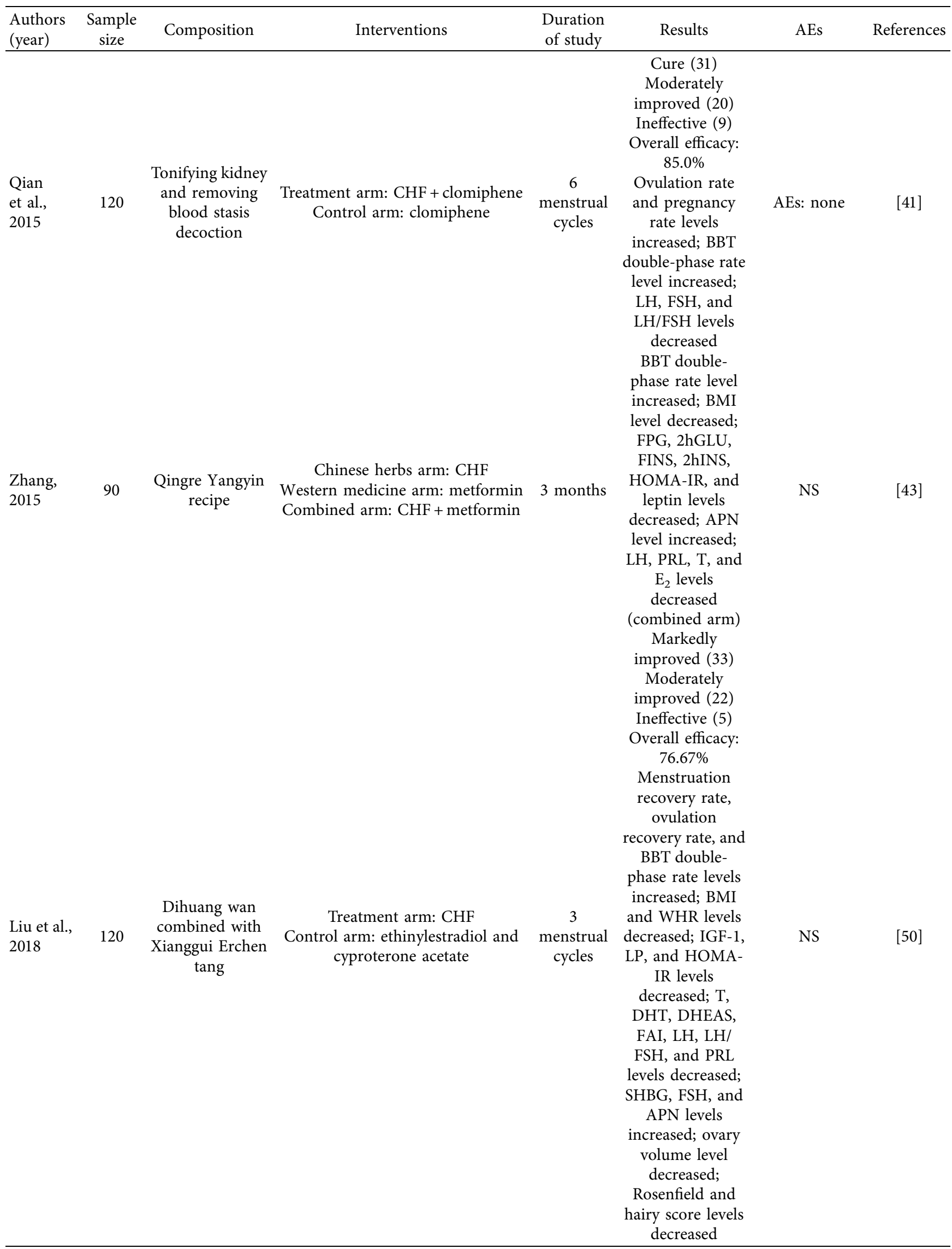


TABle 1: Continued.

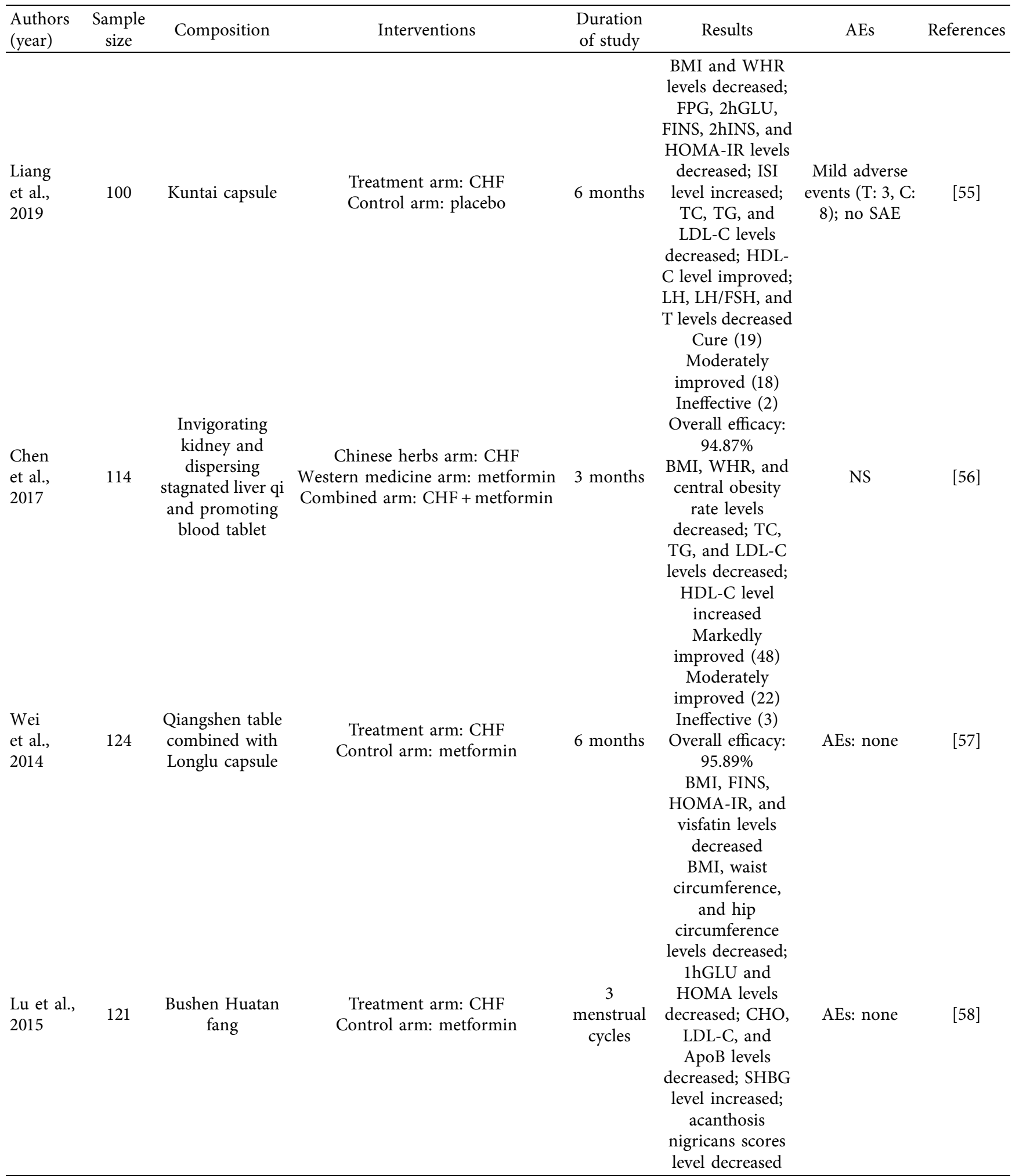


TABle 1: Continued.

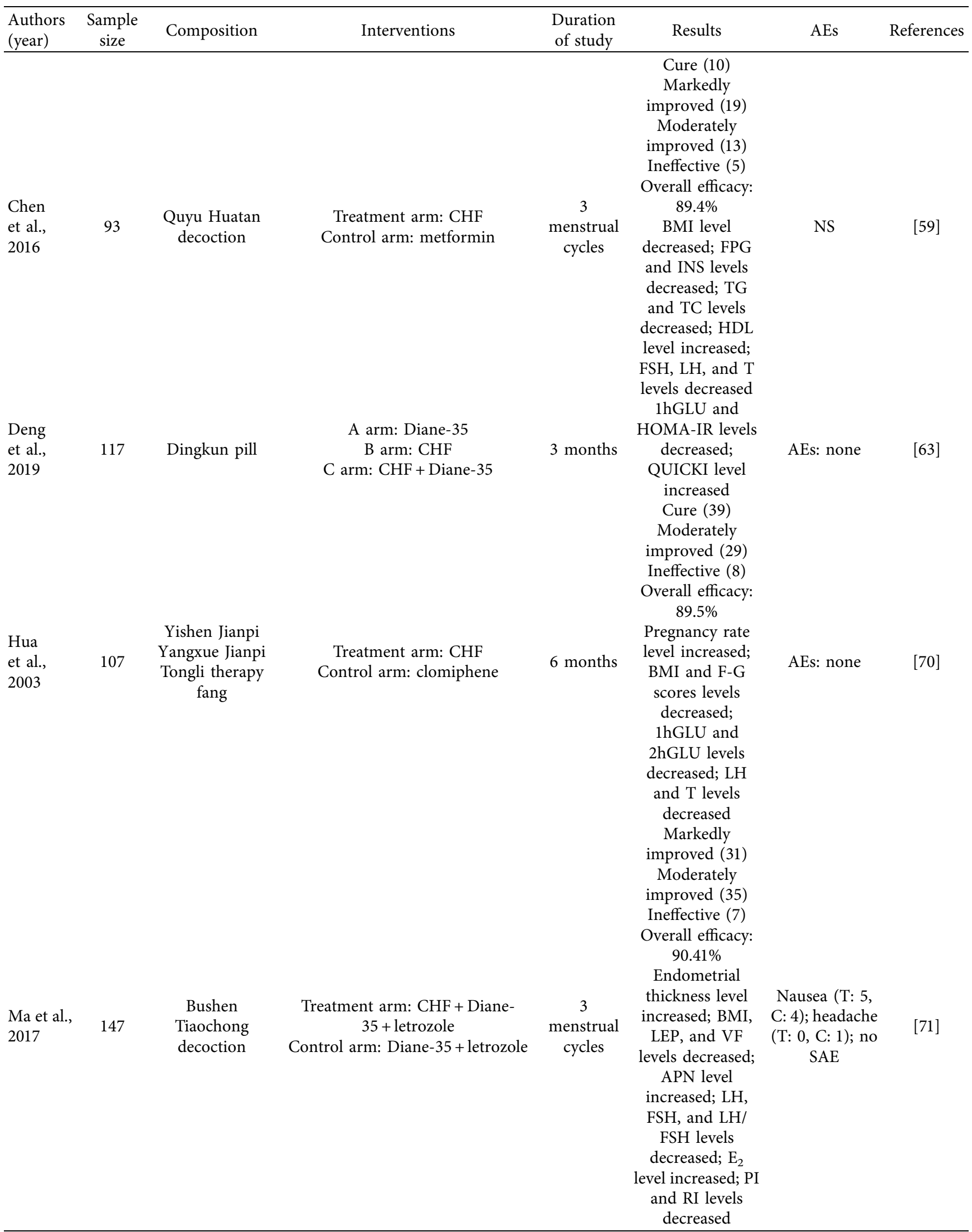


TABle 1: Continued.

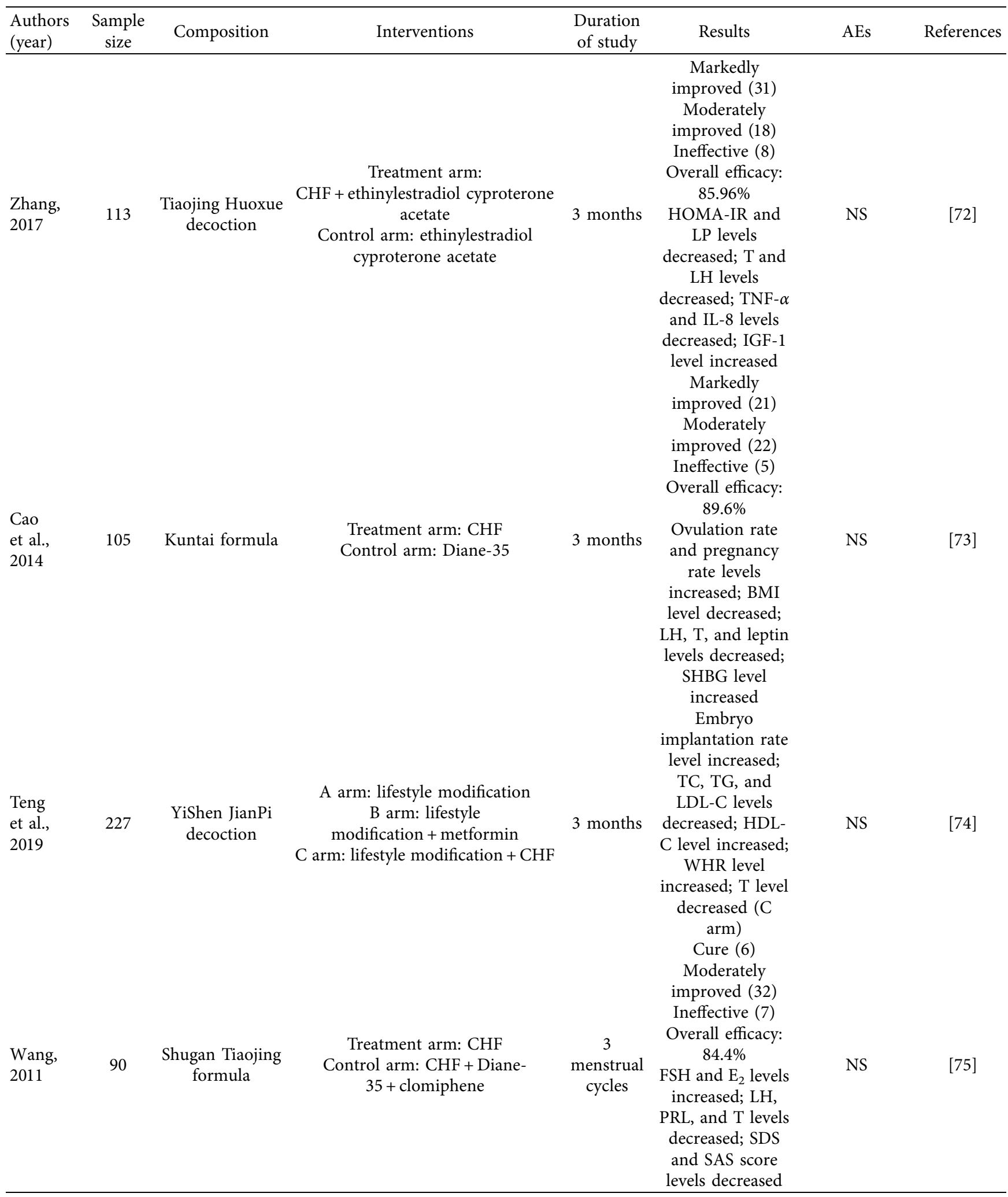


of embryo implantation. Many mechanisms have verified that the defective condition of ER can be improved by regulating endometrial thickness and endometrial morphology, when undergoing treatment with herbal formula. At the same time, herbal formula treatments also are beneficial to reduce the volume of ovary and the number of ovarian cysts [12, 44, 45, 89].

Du reported that herbal formula therapy had positive effective in endometrial thickness, type A endometrium, and menstruation recovery of infertility patient with PCOS and further found higher pregnancy rates $(52.63 \%$ versus $28.07 \%$ ) in the combination group than conventional pharmacological therapy [90]. With endometrial microcirculation disturbance, the implantation rate is low. Herbal formula can modify the endometrial microcirculation-related indicators such as resistance index and hemodynamic index and increase endometrial blood supply, and as a result, the endometrial receptivity was improved to provide good environment for embryo implantation and improve the pregnancy rate $[71,88]$. Notably, kidney herbs nourish could increase endometrial growth by promoting circulation of blood. In addition, both clinical trials and animal experiments have been certified that HF could regulate the expression of molecular biologicals, such as integrin $(\alpha v \beta 3)$, vascular endothelial growth factor (VEGF), and uncoupling protein 2 (UCP2), which are closely related to ER [21, 91, 92]. The previous study showed that using herbal formula as an adjuvant therapy has remarkable improvement effect on pulsatility index (PI) and resistance index (RI), endometrial thickness, and the expression of HOXA10 in endometria while further found higher pregnancy rates $(42.5 \%$ versus $22.5 \%$; $P<0.05)$ in the combination group compared with the control group [93]. And the animal experiment also verified these benefits that herbal formula could facilitate embryo implantation and litter size by promoting endometrium and the expression of HOXA10 [94].

The third point is that herbal formula may modulate the secretion of gonadotropin and sexual hormone via hypothalamus-pituitary ovary axis and is subsequently related to the promotion of follicular maturation and the success of ovulation [45, 50, 95]. PCOS increases the gonadotropinreleasing hormone $(\mathrm{GnRH})$ pulse rate, raises the $\mathrm{LH}$ and lowers the $\mathrm{FSH}$, and elevates $\mathrm{LH} / \mathrm{FSH}$ ratio which aggravates the secretion of androgen and restrains the form of dominant follicle, thus resulting in the state of PCOM and impairing ovulation. Some HF ameliorated sex hormones by markedly upregulating FSH level and downregulating $\mathrm{LH}$ and $\mathrm{T}$ levels as well as improving circulating $\mathrm{E}_{2}$ concentration, which could promote follicular development and induce ovulation in PCOS rats [96]. The ovarian hormones estrogen, $\mathrm{P}$, and $\mathrm{T}$ play the role in the menstrual cycle and reproductive function. Some clinical researches have exhibited that herbal formula has beneficial effects on improving menstrual cyclicity and increasing rate of ovulation by affecting plasma levels of $\mathrm{LH}, \mathrm{FSH}, \mathrm{E}_{2}, \mathrm{P}$, and $\mathrm{T}$ $[24,41,42,96]$. Research evidences also have shown herbal formula application positively affecting the ovarian architecture by increasing the number of corpus luteum and decreasing cystic and atretic follicles [97, 98].
The fourth point is that herbal formula may exhibit better antiandrogenic effect by regulating steroidogenic enzymes and steroid receptors and gonadotropin receptors. Ovary is the major source of androgen biosynthesis. In PCOS, theca cells or granule cells overexpress mRNA encoding enzymes involved in steroidogenesis, including steroidogenic acute regulatory protein (StAR), CYP11, CYP17, and CYP19, while their overexpression could cause ovarian hormone synthesis disturbance. Studies have reported that herbal formula can reinstate the balance of androgen and estrogen by rescuing the suppressed expression of LHR, FSHR, and aromatase, thus leading to improved serum $\mathrm{E}_{2}$ and $\mathrm{T}$ concentration, the changes in cystic morphologic of ovaries, and the attenuation of the disordered estrous cycle [96, 99-102]. Many CHFs play important roles on ovarian function by regulating hormone synthesis, which regulated the expression of enzymes involved in androgen synthesis, and these changes paralleled the changes in hormone level both in vivo and in vitro [99, 103, 104]. Animal studies have confirmed that Liuwei Dihuang pill and Mahuang Tang both can promote follicular development and induce ovulation and improve the ovarian polycystic pathogenesis by modulating the dysregulation of steroid hormones and steroidogenic enzymes [80, 96]. Moreover, some researchers considered that herbal formula may play a vital function in treatment by regulating some useful cytokines' expression, such as insulin-like growth factor (IGF), VEGF, tumor necrosis factor (TNF), and inflammatory cytokines expression, thereby alleviating the symptoms of PCOS [91, 92, 105].

The last point is that herbal formula can alleviate emotional distress by relieving chronic stress, which is in connection with activity of sympathetic nervous system. Adverse mental and psychological state can affect the activity of sympathetic nervous system and disturb the release of noradrenaline (NE) and nerve growth factor, thereby affecting follicular development. Recent studies suggested that adjuvant herbal formula could assist PCOS patient better, handle psychological and mood states, as well as increase the success rate of pregnancy when they received infertility treatment [15, 77]. Sun et al. found follicle development abnormality, endocrine disturbance, increased NE level, and activation of locus coeruleus in PCOS model rat, and suggested that the beneficial role of Xiaoyaosan was correlated with the regulation of the sympathetic nerve activity [106].

\subsection{The Utilization of Single Herb in Women with PCOS}

2.2.1. The Effects of Single Herb for PCOS. Single herbs use in PCOS is increasing worldwide as RCT evidence is emerging. Simple composition having no major adverse effects has made single herb medicine treatment a valuable option. Recent studies provided growing evidence that single herb medicine as CAM can help to improve health outcome and can manage the complications in women with PCOS. Many studies have revealed that single herb medicine may be a promising potent therapy in the treatment of clinical and laboratory symptoms of PCOS, including infertility, 
menstrual cyclicity, hormonal irregularities, IR, dyslipidemia, and anthropometric indices [102, 107]. Some single herbs (e.g., Salvia officinalis, Cimicifuga racemosa, and Coptidis rhizome) combined with conventional ovulation induction drugs (e.g., letrozole and clomiphene citrate) have many superiorities, such as ameliorated ovulation, thickened uterine wall thickness, increased pregnancy rates and live birth rate, as well as regulated menstruation [84, 108-111]. Two clinical trials, in China, both found that treatment with tanshinone (Salvia officinalis) before promoting ovulation could increase ovulation and pregnant rate $[112,113]$. Cimicifuga racemosa might affect infertility for PCOS not only using alone but also in combination with other medications [109, 110, 113]. Cimicifuga racemosa plus CC also could increase clinical pregnancy rates [109, 110]. Additionally, Cimicifuga racemosa used alone resulted in a significant reduction in the LH level and LH/FSH ratio as well as increase in endometrial thickness, which had similar advantages to CC in the regulation of ovulation induction [109]. Some studies have found that BBR can not only improve metabolism but also has a positive effect on reproductive endocrine and reproductive outcome in patients with PCOS $[114,115]$. Therefore, single Chinese herb may be popularized as a new inducing agent with good ovulatory rates and fewer sideeffects. There are still some controversies about the benefits from BBR (Coptidis rhizome) on fertility of PCOS. Several researches pointed out that BBR, as an assisted drug, has a positive effect on ovulation or pregnancy outcome [116]. However, a RCT showed adding BBR to letrozole did not promote fecundity in PCOS [117]. Single herb medicines also play a remarkable role in balancing menstrual pattern and the hormone status [110, 118-121]. Kort et al. investigated the effect of cinnamon on menstrual cyclicity in PCOS. After 6 months of intervention, menstrual cyclicity and menstrual flow significantly improved in cinnamon group, whereas parameters in the placebo group did not [118]. Vitex agnus was found to have the same and even better effect to oral contraceptives in menstrual regularity for PCOS with less adverse effects [122, 123]. It seems that fenugreek seeds are effective in the regulation of menstrual cyclicity and had promising effects on fertility [111].

Curcuma, Pueraria, and cinnamon have been explored to have strong anti-hyperinsulinemia, anti-hyperlipidemia, and antioxidant properties. Besides adjusted oxidative stress, Curcuma had remarkable decreased effects on BMI, FBG, serum insulin, TC, and low-density lipoprotein cholesterol (LDL-C) $[84,124,125]$. Using Curcuma along with metformin could cause a significant reduction in WHR and HOMA-IR in addition to a remarkable advance in glucose disposal rate (GDR) [84, 85, 125]. Several surveys of Salvia officinalis and Pueraria demonstrated their efficacy in the regulation of metabolic parameters and menstrual cycles [126-130]. Amini et al. also showed that the consumption of Salvia officinalis extract could lead to a statistically decrease in BW, waist circumference (WC), and diastolic blood pressure level [130]. The results also showed significant improvements in glycemic control and insulin sensitivity due to the levels of insulin, FBG and HOMA-IR were markedly decreased, and the quantitative insulin sensitivity check index (QUICKI) was observably increased in the Salvia officinalis group. A survey reported the advantageous impact of Pueraria on normalizing the menstrual cycle, IR markers, and serum level of triglyceride when used for 12 weeks [131]. Cinnamon and Curcuma have similar therapeutic effects on glucolipid profile, such as reducing FBG, IR, TC, and TG and enhancing HDL-C level [132-134]. However, there still are different opposite opinions, and some experts suggest that administration of cinnamon may not improve IR and serum TG level $[118,134]$. The inconsistent effect of single herb treatment for PCOS may due to the differences in sample size, duration of use, dosage, and different drug forms. We have listed some studies' results in Table 2.

2.2.2. The Mechanisms of Single Herbs for PCOS. The main mechanisms of the effectiveness of single herbs (extract) in PCOS are not yet fully understood. Nevertheless, the following points deserve careful consideration. The first point is that single herb may improve the menstrual cycle, ovulation, and fertility by regulating the secretion of endocrine hormones. Single herb may act directly on the hypothalamus to affect the hypothalamo-pituitary axis and reduce the release of gonadotrophin-releasing hormone, therefore improving the hormonal balance of $\mathrm{LH}, \mathrm{FSH}$, and T $[133,135,136]$. Reduction of the LH level increases the sensitivity of ovarian tissue to circulating FSH, contributing to alleviation of the symptoms of excessive androgens, the follicular growth, and ovulation. Also, single herbs have estrogen-like function, which was directly related to improve the implantation rate and pregnancy outcome, and can decrease the serum level of androgens by increasing the level of SHBG [137]. It has been proved that Vitex agnus could regulate the menstrual frequency and enhance fertility capacity by inducing the growth in the level of midluteal $\mathrm{P}$, normalizing $\mathrm{FSH}$ and $\mathrm{LH}$ release, as well as inhibition of type II dopamine receptors [138]. The single herb may have agonistic and/or antagonistic effects on different oestrogenic receptors.

The second point is that single herb can reduce the IR and improve glucose homeostasis parameters of PCOS by affecting the insulin signaling pathways, which manage insulin-stimulated glucose uptake and glycogen synthesis $[139,140]$. The animal studies have displayed that the extract isolated from the single herb, including flavonoids, polyphenols, diterpenoids, and triterpenoids, can potentiate glycogen synthesis increase, stimulate glucose uptake, and increase insulin sensitivity by activating insulin receptors and stimulating autophosphorylation of the insulin receptors $[139,141]$. Polyphenol polymers, for instance, can exert better hypoglycemic effects by reinforcing insulin signaling at the postreceptor level and stimulating PI3K activity, and consequently, the activation of this pathway could cause the translocation of glucose transporter (GLUT) receptors, finally advancing glucose utilization by facilitating intracellular glucose transport and increasing glycogen synthesis.

The third point is the hypoglycemic effect of single herb may be related with stimulation of insulin synthesis and 
TABLE 2: Summary of the effect of randomized studies of single herb on PCOS outcomes.

\begin{tabular}{|c|c|c|c|c|c|c|c|}
\hline $\begin{array}{l}\text { Authors } \\
\text { (year) }\end{array}$ & $\begin{array}{l}\text { Herbal } \\
\text { medicine } \\
\text { Scientific } \\
\text { name }\end{array}$ & $\begin{array}{l}\text { Extract and } \\
\text { dosage form }\end{array}$ & Interventions & $\begin{array}{c}\text { Study } \\
\text { duration }\end{array}$ & Results & AEs & References \\
\hline $\begin{array}{l}\text { Jamilian } \\
\text { et al., } 2020\end{array}$ & $\begin{array}{l}\text { Rhizoma } \\
\text { Curcumae }\end{array}$ & $\begin{array}{l}\text { Curcumin } \\
\text { capsule }\end{array}$ & $\begin{array}{l}\text { Treatment arm: curcumin } \\
\text { Control arm: placebo }\end{array}$ & 12 weeks & $\begin{array}{l}\text { BMI and weight } \\
\text { levels decreased; } \\
\text { FPG, FINS, and } \\
\text { HOMA-IR levels } \\
\text { decreased; } \\
\text { QUICKI level } \\
\text { increased; TC and } \\
\text { LDL-C levels } \\
\text { decreased; HDL-C } \\
\text { level increased; } \\
\text { PPAR-g and LDLR } \\
\text { gene expression } \\
\text { levels increased }\end{array}$ & NS & {$[84]$} \\
\hline $\begin{array}{l}\text { Wu et al., } \\
2019\end{array}$ & $\begin{array}{l}\text { Rhizoma } \\
\text { Curcumae }\end{array}$ & $\begin{array}{l}\text { Curcuma } \\
\text { water } \\
\text { decoction }\end{array}$ & $\begin{array}{c}\text { Treatment arm: } \\
\text { curcuma + metformin } \\
\text { Control arm: metformin }\end{array}$ & $\begin{array}{c}3 \\
\text { months }\end{array}$ & $\begin{array}{c}\text { BMI and WHR } \\
\text { levels decreased; } \\
\text { TC, TG, and LDL- } \\
\text { C levels decreased; } \\
\text { HDL-C level } \\
\text { increased; FAI and } \\
\text { LH/FSH levels } \\
\text { decreased; FPG, } \\
\text { 2hGLU, FINS, } \\
\text { 2hINS, HbA1c, and } \\
\text { HOMA-IR levels } \\
\text { decreased }\end{array}$ & $\begin{array}{c}\text { Gastrointestinal } \\
\text { complications, } \\
\text { dizziness, pruritus, } \\
\text { and edema (T: } 10, \mathrm{C} \text { : } \\
\text { 13) }\end{array}$ & [85] \\
\hline $\begin{array}{l}\text { Wang } \\
\text { et al., } 2011\end{array}$ & $\begin{array}{l}\text { Rhizoma } \\
\text { Coptidis }\end{array}$ & $\begin{array}{l}\text { Berberine } \\
\text { tablet }\end{array}$ & $\begin{array}{c}\text { Treatment arm: } \\
\text { berberine + metformin } \\
\text { Control arm: metformin }\end{array}$ & $\begin{array}{c}3 \\
\text { months }\end{array}$ & $\begin{array}{l}\text { Ovulation rate level } \\
\text { increased; BMI, } \\
\text { FIN, and HOMA- } \\
\text { IR levels decreased; } \\
\text { LH, LH/FSH, and } \\
\text { T levels decreased } \\
\text { LH and FSH/LH }\end{array}$ & NS & [108] \\
\hline $\begin{array}{l}\text { Kamel, } \\
2013\end{array}$ & $\begin{array}{l}\text { Rhizoma } \\
\text { Cimicifugae }\end{array}$ & Klimadynon & $\begin{array}{l}\text { Treatment arm: klimadynon } \\
\text { Control arm: clomiphene }\end{array}$ & $\begin{array}{c}3 \\
\text { months }\end{array}$ & $\begin{array}{l}\text { levels decreased; P } \\
\text { level increased; } \\
\text { endometrial } \\
\text { thickness level } \\
\text { increased }\end{array}$ & $\begin{array}{l}\text { Hyperstimulation } \\
\text { (T: } 1, \mathrm{C}: 2)\end{array}$ & [109] \\
\hline $\begin{array}{l}\text { Bashtian } \\
\text { et al., } 2013\end{array}$ & $\begin{array}{c}\text { Semen } \\
\text { Trigonellae }\end{array}$ & $\begin{array}{l}\text { Fenugreek } \\
\text { seed extract } \\
\text { as capsule }\end{array}$ & $\begin{array}{c}\text { Treatment arm: } \\
\text { fenugreek + metformin } \\
\text { Control arm: } \\
\text { placebo + metformin }\end{array}$ & 8 weeks & $\begin{array}{l}\text { Menstrual cyclicity } \\
\text { improved; } \\
\text { polycystic- } \\
\text { appearing ovaries } \\
\text { decreased }\end{array}$ & AEs: none & [111] \\
\hline $\begin{array}{l}\text { Wang } \\
\text { et al., } 2016\end{array}$ & $\begin{array}{l}\text { Radix } \\
\text { Salviae }\end{array}$ & $\begin{array}{l}\text { Tanshinone } \\
\text { capsule }\end{array}$ & $\begin{array}{c}\text { Treatment arm: } \\
\text { tanshinone + letrozole } \\
\text { Control arm: } \\
\text { placebo + letrozole }\end{array}$ & $\begin{array}{c}3 \\
\text { months }\end{array}$ & $\begin{array}{c}\text { Ovulation rate and } \\
\text { pregnancy rate } \\
\text { levels increased; } \\
\text { BMI level } \\
\text { decreased; TC and } \\
\text { TG levels } \\
\text { decreased; LH, } \\
\text { FSH, and T levels } \\
\text { decreased }\end{array}$ & NS & [112] \\
\hline
\end{tabular}


TABle 2: Continued.

\begin{tabular}{|c|c|c|c|c|c|c|c|}
\hline $\begin{array}{l}\text { Authors } \\
\text { (year) }\end{array}$ & $\begin{array}{l}\text { Herbal } \\
\text { medicine } \\
\text { Scientific } \\
\text { name }\end{array}$ & $\begin{array}{l}\text { Extract and } \\
\text { dosage form }\end{array}$ & Interventions & $\begin{array}{l}\text { Study } \\
\text { duration }\end{array}$ & Results & AEs & References \\
\hline $\begin{array}{l}\text { Li et al., } \\
2017\end{array}$ & $\begin{array}{l}\text { Rhizoma } \\
\text { Coptidis }\end{array}$ & $\begin{array}{l}\text { Berberine } \\
\text { capsule }\end{array}$ & $\begin{array}{l}\text { Treatment arm: berberine } \\
\text { Control arm: metformin }\end{array}$ & $\begin{array}{c}3 \\
\text { months }\end{array}$ & $\begin{array}{l}\text { BMI, HOMA-IR, } \\
\text { FPG, FINS, and } \\
\text { 2hINS levels } \\
\text { decreased; TC, TG, } \\
\text { and LDL-C levels } \\
\text { decreased; LH, LH/ } \\
\text { FSH, and T levels } \\
\text { decreased } \\
\text { HOMA-IR level }\end{array}$ & $\begin{array}{l}\text { Gastrointestinal } \\
\text { complications (T: } 0 \text {, } \\
\text { C: } 1 \text { ) }\end{array}$ & [114] \\
\hline $\begin{array}{l}\text { Li et al., } \\
2015\end{array}$ & $\begin{array}{l}\text { Rhizoma } \\
\text { Coptidis }\end{array}$ & Berberine & $\begin{array}{c}\text { Treatment arm: } \\
\text { berberine + dydrogesterone } \\
\text { Control arm: } \\
\text { dydrogesterone }\end{array}$ & $\begin{array}{c}3 \\
\text { months }\end{array}$ & $\begin{array}{c}\text { decreased; TC and } \\
\text { TG levels } \\
\text { decreased; LH, } \\
\text { FSH, T, DHEA, } \\
\text { and A levels } \\
\text { decreased }\end{array}$ & NS & [115] \\
\hline $\begin{array}{l}\text { An et al., } \\
2014\end{array}$ & $\begin{array}{l}\text { Rhizoma } \\
\text { Coptidis }\end{array}$ & $\begin{array}{l}\text { Berberine } \\
\text { tablet }\end{array}$ & $\begin{array}{l}\text { BBR arm: berberine } \\
\text { MET arm: metformin } \\
\text { Placebo arm: placebo }\end{array}$ & $\begin{array}{c}3 \\
\text { months }\end{array}$ & $\begin{array}{l}\text { Live birth rate level } \\
\text { increased; BMI and } \\
\text { WHR levels } \\
\text { decreased; TC and } \\
\text { LDL-C levels } \\
\text { decreased (BBR } \\
\text { arm) }\end{array}$ & $\begin{array}{l}\text { Nausea (MET: 12, } \\
\text { BBR: 9, placebo: 4), } \\
\text { OHSS (MET: 2, BBR: } \\
\text { 2, Placebo: 6), no } \\
\text { SAE }\end{array}$ & [116] \\
\hline $\begin{array}{l}\text { Wu et al., } \\
2016\end{array}$ & $\begin{array}{l}\text { Rhizoma } \\
\text { Coptidis }\end{array}$ & $\begin{array}{l}\text { Berberine } \\
\text { capsule }\end{array}$ & $\begin{array}{c}\text { Letrozole arm: } \\
\text { letrozole + berberine } \\
\text { placebo } \\
\text { Berberine arm: } \\
\text { berberine + letrozole } \\
\text { placebo } \\
\text { Combination arm: } \\
\text { letrozole + berberine }\end{array}$ & $\begin{array}{c}6 \\
\text { months }\end{array}$ & $\begin{array}{c}\text { Ovulation rate level } \\
\text { mild } \\
\text { Increased } \\
\text { (combination } \\
\text { arm); BMI and } \\
\text { waist } \\
\text { circumference } \\
\text { levels decreased } \\
\text { (berberine arm) }\end{array}$ & $\begin{array}{l}\text { Mild in three arms: } \\
\text { gastrointestinal } \\
\text { complications in } \\
\text { three groups; no SAE }\end{array}$ & [117] \\
\hline $\begin{array}{l}\text { Kort et al., } \\
2014\end{array}$ & $\begin{array}{c}\text { Cortex } \\
\text { Cinnamomi }\end{array}$ & $\begin{array}{l}\text { Cinnamon } \\
\text { capsule }\end{array}$ & $\begin{array}{l}\text { Treatment arm: cinnamon } \\
\text { Control arm: placebo }\end{array}$ & $\begin{array}{c}6 \\
\text { months }\end{array}$ & $\begin{array}{l}\text { Menstrual cyclicity } \\
\text { improved }\end{array}$ & NS & [118] \\
\hline $\begin{array}{l}\text { Sohaei } \\
\text { et al., } 2019\end{array}$ & $\begin{array}{l}\text { Rhizoma } \\
\text { Curcumae }\end{array}$ & Curcumin & $\begin{array}{c}\text { Treatment arm: } \\
\text { curcumin + metformin } \\
\text { Control arm: } \\
\text { placebo + metformin }\end{array}$ & 6 weeks & $\begin{array}{l}\text { FINS and HOMA- } \\
\text { IR levels decreased; } \\
\text { QUICKI level } \\
\text { increased }\end{array}$ & $\begin{array}{c}\text { Gastrointestinal } \\
\text { complications ( } \mathrm{T}: 3 \text {, } \\
\text { C: } 0 \text { ) }\end{array}$ & [124] \\
\hline $\begin{array}{l}\text { Heshmati } \\
\text { et al., } 2020\end{array}$ & $\begin{array}{l}\text { Rhizoma } \\
\text { Curcumae }\end{array}$ & $\begin{array}{l}\text { Curcumin } \\
\text { capsule }\end{array}$ & $\begin{array}{l}\text { Treatment: curcumin } \\
\text { Control arm: placebo }\end{array}$ & $\begin{array}{c}3 \\
\text { months }\end{array}$ & $\begin{array}{l}\text { GPx level } \\
\text { increased; SIRT1 } \\
\text { and PGC-1a gene } \\
\text { expression levels } \\
\text { increased }\end{array}$ & AEs: none & [125] \\
\hline $\begin{array}{l}\text { Su et al., } \\
2015\end{array}$ & $\begin{array}{l}\text { Radix } \\
\text { Salviae }\end{array}$ & $\begin{array}{l}\text { Tanshinone } \\
\text { capsule }\end{array}$ & $\begin{array}{l}\text { Treatment arm: tanshinone } \\
\text { Control arm: placebo }\end{array}$ & $\begin{array}{c}3 \\
\text { months }\end{array}$ & $\begin{array}{c}\text { 1hGLU and } \\
\text { 2hGLU levels } \\
\text { decreased; serum } \\
\text { glucose clearance } \\
\text { rate level increased }\end{array}$ & NS & [126] \\
\hline $\begin{array}{l}\text { Zhang } \\
\text { et al., } 2015\end{array}$ & $\begin{array}{l}\text { Radix } \\
\text { Salviae }\end{array}$ & $\begin{array}{l}\text { Tanshinone } \\
\text { capsule }\end{array}$ & $\begin{array}{l}\text { Treatment arm: tanshinone } \\
\text { Control arm: placebo }\end{array}$ & $\begin{array}{c}3 \\
\text { months }\end{array}$ & $\begin{array}{l}\text { TC and TG levels } \\
\text { decreased; HDL-C } \\
\text { level increased; T } \\
\text { level decreased }\end{array}$ & AEs: none & [127] \\
\hline
\end{tabular}


TABLE 2: Continued.

\begin{tabular}{|c|c|c|c|c|c|c|c|}
\hline $\begin{array}{l}\text { Authors } \\
\text { (year) }\end{array}$ & $\begin{array}{l}\text { Herbal } \\
\text { medicine } \\
\text { Scientific } \\
\text { name }\end{array}$ & $\begin{array}{l}\text { Extract and } \\
\text { dosage form }\end{array}$ & Interventions & $\begin{array}{l}\text { Study } \\
\text { duration }\end{array}$ & Results & AEs & References \\
\hline $\begin{array}{l}\text { Wu et al., } \\
2016\end{array}$ & $\begin{array}{l}\text { Radix } \\
\text { Salviae }\end{array}$ & $\begin{array}{l}\text { Tanshinone } \\
\text { capsule }\end{array}$ & $\begin{array}{c}\text { Treatment arm: } \\
\text { tanshinone + Diane-35 } \\
\text { Control arm: Diane-35 }\end{array}$ & $\begin{array}{c}3 \\
\text { months }\end{array}$ & $\begin{array}{l}\text { TC, TG, and LDL- } \\
\text { C levels decreased; } \\
\text { HDL-C level } \\
\text { increased; LH and } \\
\text { TSH levels } \\
\text { decreased; GH level } \\
\text { increased; ACTH, } \\
\beta \text {-EP, Cor, and } \\
\text { UFC levels } \\
\text { decreased }\end{array}$ & NS & [128] \\
\hline $\begin{array}{l}\text { Li et al., } \\
2017\end{array}$ & $\begin{array}{c}\text { Radix } \\
\text { Puerariae }\end{array}$ & $\begin{array}{l}\text { Puerarin } \\
\text { tablet }\end{array}$ & $\begin{array}{l}\text { Obesity treatment arm: } \\
\text { puerarin + Diane- } \\
35+\text { metformin } \\
\text { Thin treatment arm: } \\
\text { puerarin + Diane- } \\
35+\text { metformin } \\
\text { Obesity control arm: Diane- } \\
35+\text { metformin }\end{array}$ & $\begin{array}{c}3 \\
\text { months }\end{array}$ & $\begin{array}{c}\text { Menstrual cyclicity } \\
\text { improved; BMI } \\
\text { level decreased; } \\
\text { HOMA-IS level } \\
\text { decreased; TC and } \\
\text { TG levels } \\
\text { decreased; HDL-C } \\
\text { level increased; } \\
\text { SOD level } \\
\text { increased; T level } \\
\text { decreased; (obesity } \\
\text { treatment arm) }\end{array}$ & NS & [131] \\
\hline $\begin{array}{l}\text { Khan } \\
\text { et al., } 2018\end{array}$ & $\begin{array}{c}\text { Cortex } \\
\text { Cinnamomi }\end{array}$ & $\begin{array}{l}\text { Cinnamon } \\
\text { extract as } \\
\text { capsule }\end{array}$ & $\begin{array}{l}\text { Treatment arm: cinnamon } \\
\text { Control arm: placebo }\end{array}$ & 8 weeks & $\begin{array}{c}\text { Menstrual cyclicity } \\
\text { improved; ovarian } \\
\text { size level decreased; } \\
\text { FT level decreased } \\
\text { FPG and HOMA- } \\
\text { IR levels decreased; } \\
\text { QUICKI and } \\
\text { matsuda insulin } \\
\text { resistance index } \\
\text { levels increased }\end{array}$ & $\begin{array}{c}\text { Epigastric burning } \\
\text { and belching (T: } 1, \mathrm{C} \text { : } \\
\text { 1); no SAE }\end{array}$ & {$[136]$} \\
\hline
\end{tabular}

secretion from the beta-pancreatic cells of Langerhans [142]. There also is a cognition that single herb could affect the activity of digestive enzymes, such as pancreatic and intestinal lipase, alpha-amylase, and pyruvate kinase, which are involved in the digestion and absorption of glucose and lipid [143]. Lastly, the single herb may modulate the expression of genes closely related to cellular glucose absorption and metabolism [144].

\section{The Utilization of Acupuncture Combined with Herbal Medicine}

Acupuncture involves the insertion and retaining of very fine needles into specific anatomical points and has been used in eastern Asian countries to regulate the women's health disorders for many centuries. The major theory of acupuncture is based on Chinese medical theory which believes that there is a kind of energy flow through the body; when the energy flow is represented as a balance of Yin and Yang or Qi and Xue, the body is disease-free. In view of the high security of acupuncture treatment, transient adverse effects including pain, bleeding, redness, and hematomas are uncommon. Acupuncture therapy is now accepted, worldwide, as a kind of therapy of CAM. As early as two 2500 years ago, doctors are often used in combination with acupuncture and Chinese medicinal herbs together to treat gynaecological diseases in China. The Handbook of Prescription for Emergencies describe that "Those who apply acupuncture without medicine or medicine without acupuncture are especially not good doctors. Those who know both medicine and acupuncture are good doctors." More importantly, herbal medicine combined with acupuncture has advantages over each alone.

A RCT trial was delivered in hospital of China in oligomenorrhea women with PCOS, and 88 patients were randomized $(1: 1)$ to abdominal acupuncture-medicine group or abdominal acupuncture for 3 months. During the 3 months of intervention, menstrual cycles were more frequent and menstrual blood volume was more increased in patients receiving acupuncture and Bushen Huoxue decoction compared with patients receiving acupuncture $(P<0.05)$ [145]. Acupuncture therapy adjuvant to HM could affect reproductive endocrinology and medium- to longterm functional outcome $[146,147]$. Yin et al. not only found statistically significant improvements in menstrual rates but also found the BW and $\mathrm{AMH}$ were significantly lower; 
however, the ovulation and pregnancy rates were higher in the acupuncture-herbal medicine group than the control group in 120 infertility women with PCOS [147].

Electroacupuncture (EA) is considered to be an effective alternative to conventional needle acupuncture, is valuable in patients with PCOS, is a therapy where fine needles are placed in the skin and underly muscle tissue at specific areas of the body, and then input current flow in the near human body bioelectricity. Yu and Liao randomized 67 cases of obese patients of PCOS to the combination group and control group, combination group was treated with EA and Tiankui capsule, and control group was only treated with EA [148]. Results showed that BMI, WHR, BW, and FINS decreased and ISI and APN were higher in the combination group than that in the control group $(P<0.01)$. Su et al. also found the similar results; moreover, there were significantly improvement of $\mathrm{LH}, \mathrm{LH} / \mathrm{FSH}, \mathrm{T}$, and leptin in this study [149]. The combination treatment could better alleviate the symptoms and endocrine indices, insulin sensitivity, leptin, and APN levels, to improve the quality of life of women with PCOS. Overall, in recent ten years, many RCTs have proved that the combination of acupuncture and herbal medicine has positive impact on reproductive dysfunction, endocrine disorder, and abnormal glucolipid metabolism in PCOS $[145,146,148-150]$. The possible mechanisms of action of acupuncture for PCOS are as follows: (i) lower high sympathetic nerve activity and regulate parasympathetic and sympathetic activity; (ii) regulate the central nervous system through the hypothalamus-pituitary-ovary (HPO) axis and hypothalamus-pituitary-adrenal (HPA) axis; (iii) modulate the metabolic system by modulating expression of genes related to IR, obesity, and sympathetic activity in skeletal muscle and adipose tissue [151-153]. The animal study confirmed that combination of acupuncture and medicinal herb significantly enhanced curative effects by improving the absorption of salvianolic acid B which were extracted from the Chinese medicine formula in the PCOS rat mode [154]. The research of $\mathrm{Yu}$ revealed that the mechanism of combination would be EA plus herbal medicine can restore the equilibrium between Yin and Yang, as well as Qi and blood; recover kidney function, the chong and conception vessels, and the uterus; and improve endocrine function and ovarian microcirculation [148].

\section{Dietetic Therapy and Its Mechanism of Action in PCOS}

Dietetic therapy is one of the key components of TCM, according to traditional theory of TCM, and food is considered as medication. As food and medication are the same in terms of nature, origin, taste, and function, they are equally important in preventing and curing diseases [155]. Moreover, food is considered as tonic, which can treat various deficiencies including "Yin," "Yang," "Qi," and "Xue," and it can help individuals smooth body mechanisms and facilitate rehabilitation. Dietetic therapy insists that different foods have different effects on "Yin" and "Yang," "Qi" and "Xue," and "Zang Fu" organs. Fitting dietetic therapy can nourish "Zang Fu" organs and promote the rehabilitation; oppositely, unfitting diet will lead to the imbalance of "Yin Yang" and "Qi Xue," even the unhealthy condition of "Zang Fu" organs. Dietetic therapy has played an important role in auxiliary treatment for PCOS. Tea, soup, and porridge are most common forms of TCM dietetic therapy. Dietetic therapies are quite suitable for PCOS patients, particularly in women who intend to be conceptive. Both meat soup and rice porridge add some herbals such as Radix Astragali Seu Hedysari, Rhizoma Polygonati Odorati, Rhizoma Dioscoreae, and Radix Ophiopogonis, to promote microcirculation and reproductive endocrine function of the ovary [156, 157].

All these foods have therapeutic effects, and these are what the doctor provided as therapy to patient, according to individual's health condition and physical problems. The food can nourish kidney, strengthen spleen, regulate Qi flow, and generate blood. Modern pharmacological research discovers that the adjunct ingredients Radix Astragali Seu Hedysari, Radix Ginseng, and Radix Ophiopogonis contain polysaccharide fractions which have antioxidant, antidiabetic, hypolipidemic, and immunomodulatory activities [158]. Many herbs, meanwhile, are rich in diosgenin which contains some synthetic materials necessary for steroid hormones, and these herbs have a similar effect as sex hormones and can promote gonadal. Recently, tea as a natural herbal medicine also has been widely considered in treating PCOS and has been intensely researched. Green tea, a commonly consumed beverage in Asia, has been found to exert beneficial effects on the endocrine system, on glucose and lipid metabolic. The latest findings of Tehrani et al. show that green tea consumption has a significant effect on overweight and obese women with PCOS, leading to weight loss and a drop in fasting insulin and free testosterone level [159]. Other studies also found that the weight, BMI, waist, and hip circumference in the green tea group were markedly declined $[160,161]$. In a prospective, double-blind, placebocontrolled RCT, Grant found that spearmint herbal tea has significant antiandrogen effects, and it may be a natural and helpful treatment for hirsutism in PCOS [162]. Marjoram tea showed beneficial effects on the hormonal indicator of PCOS women, improving insulin sensitivity and reducing the levels of adrenal androgens [163]. However, when the doses of green tea were inadequate, different study had different results about glucose and lipid profile [164]. We have listed some clinical trials in Table 3.

In general, the major potential mechanisms in the support of PCOS women's health by tea involve the following [165, 166]: (i) antioxidant properties, anti-hyperlipidemic, and anti-diabetic activity; (ii) reducing carbohydrate absorption by inhibition of various digestive enzymes; (iii) increased glucose uptake in skeletal muscle, while decreased glucose uptake in adipose tissue.

\section{Moxibustion on Patients with PCOS}

Moxibustion is a noninvasive CAM therapy which has the advantage of good clinical efficacy and no toxic effects. It is characterized by the use of moxa as burning material directly or indirectly at acupoints. TCM theory considers that 
TABLE 3: Summary of the effect of randomized studies of dietetic therapy on PCOS outcomes.

\begin{tabular}{|c|c|c|c|c|c|c|}
\hline $\begin{array}{l}\text { Authors } \\
\text { (year) }\end{array}$ & Design & Form and composition & Interventions & $\begin{array}{l}\text { Duration } \\
\text { of study }\end{array}$ & Results & References \\
\hline $\begin{array}{l}\text { Liu et al., } \\
2017\end{array}$ & RCT & $\begin{array}{c}\text { POT: Radix Astragali seu } \\
\text { Hedysari + Rhizoma } \\
\text { Polygonati + Rhizoma } \\
\text { Dioscoreae + Herba } \\
\text { Dendrobii + Radix Morindae } \\
\text { Officinalis + equal }\end{array}$ & $\begin{array}{c}\text { Treatment arm: oral warm } \\
\text { nest pot }+ \text { letrozole } \\
\text { Control arm: letrozole }\end{array}$ & 3 months & $\begin{array}{c}\text { Markedly improved } \\
(24) \\
\text { Moderately } \\
\text { improved (8) } \\
\text { Ineffective (5) } \\
\text { Overall efficacy: } \\
87.18 \% \\
\text { Ovulation rate level } \\
\text { increased; menstrual } \\
\text { cyclicity improved }\end{array}$ & {$[156]$} \\
\hline $\begin{array}{l}\text { Liu et al., } \\
2019\end{array}$ & RCT & $\begin{array}{l}\text { Porridge and Tea: (1) Poria Rhizoma } \\
\text { Dioscoreae Porridge: Poria } \\
\text { Rhizoma + Dioscoreae + rice } \\
\text { (2) Pericarpium Citri Reticulatae } \\
\text { Fructus Hordei Germinatus } \\
\text { Porridge: Pericarpium Citri } \\
\text { Reticulatae + Fructus Hordei } \\
\text { Germinatus + rice } \\
\text { (3) Fructus Lycii Rhizoma } \\
\text { Dioscoreae Porridge: Fructus } \\
\text { Lycii + Rhizoma Dioscoreae + rice } \\
\text { (4) Fructus Citri Sarcodactylis } \\
\text { Pericarpium Citri Reticulatae tea: } \\
\text { Fructus Citri } \\
\text { Sarcodactylis + Pericarpium Citri } \\
\text { Reticulatae + tea } \\
\text { (5) Flos Rosae Rugosae Fructus Citri } \\
\text { Sarcodactylis tea: Flos Rosae } \\
\text { Rugosae + Fructus Citri } \\
\text { Sarcodactylis + tea }\end{array}$ & $\begin{array}{l}\text { Treatment arm: } \\
\text { dietotherapy + acupoint } \\
\text { embedding therapy } \\
\text { Control arm: acupoint } \\
\text { embedding therapy }\end{array}$ & 3 months & $\begin{array}{c}\text { Markedly improved } \\
(17) \\
\text { Moderately } \\
\text { improved (22) } \\
\text { Ineffective (4) } \\
\text { Overall efficacy: } \\
90.7 \%\end{array}$ & {$[157]$} \\
\hline $\begin{array}{l}\text { Tehrani } \\
\text { et al., } 2017\end{array}$ & $\begin{array}{l}\text { RCT/ } \\
\text { double- } \\
\text { blind }\end{array}$ & Tea: green tea & $\begin{array}{l}\text { Treatment arm: tea } \\
\text { Control arm: placebo }\end{array}$ & 12 weeks & $\begin{array}{l}\text { Weight and fasting } \\
\text { insulin levels } \\
\text { decreased; FT levels } \\
\text { decreased }\end{array}$ & [159] \\
\hline $\begin{array}{l}\text { Farhadian } \\
\text { et al., } 2020\end{array}$ & $\begin{array}{l}\text { RCT/ } \\
\text { double- } \\
\text { blind }\end{array}$ & Tea: green tea & $\begin{array}{l}\text { Green tea arm: tea } \\
\text { Metformin arm: } \\
\text { metformin } \\
\text { Control arm: placebo }\end{array}$ & 3 months & $\begin{array}{l}\text { BMI, weight, waist } \\
\text { circumference, and } \\
\text { hip circumference } \\
\text { levels decreased }\end{array}$ & {$[160]$} \\
\hline $\begin{array}{l}\text { Mombaini } \\
\text { et al., } 2017\end{array}$ & $\begin{array}{l}\text { RCT/ } \\
\text { double- } \\
\text { blind }\end{array}$ & Tea: green tea & $\begin{array}{l}\text { Treatment arm: tea } \\
\text { Control arm: placebo }\end{array}$ & 45 days & $\begin{array}{l}\text { BMI, weight, body } \\
\text { fat, waist } \\
\text { circumference, and } \\
\text { hip circumference } \\
\text { levels decreased } \\
\text { FT and TT levels }\end{array}$ & [161] \\
\hline Grant, 2010 & $\begin{array}{l}\text { RCT/ } \\
\text { double- } \\
\text { blind }\end{array}$ & Tea: spearmint tea & $\begin{array}{l}\text { Treatment arm: tea } \\
\text { Control arm: placebo } \\
\text { herbal tea }\end{array}$ & 1 month & $\begin{array}{l}\text { FT and TT levels } \\
\text { decreased; FSH and } \\
\text { LH levels increased; } \\
\text { hirsutism scored } \\
\text { level decreased }\end{array}$ & {$[162]$} \\
\hline $\begin{array}{l}\text { Haj-Husein } \\
\text { et al., } 2016\end{array}$ & $\begin{array}{l}\text { RCT/ } \\
\text { double- } \\
\text { blind }\end{array}$ & Tea: marjoram tea & $\begin{array}{l}\text { Treatment arm: tea } \\
\text { Control arm: placebo }\end{array}$ & 1 month & $\begin{array}{l}\text { HOMA-IR level } \\
\text { decreased; DHEA-S } \\
\text { level decreased }\end{array}$ & {$[163]$} \\
\hline $\begin{array}{l}\text { Chan et al., } \\
2006\end{array}$ & $\begin{array}{l}\text { RCT/ } \\
\text { double- } \\
\text { blind }\end{array}$ & Tea: Lung Chen tea & $\begin{array}{l}\text { Treatment arm: tea } \\
\text { Control arm: placebo }\end{array}$ & 3 months & $\begin{array}{c}\text { Weight level } \\
\text { decreased; TC level } \\
\text { decreased }\end{array}$ & {$[164]$} \\
\hline
\end{tabular}

moxibustion therapy can not only dredge meridians and regulate qi-blood but also has a dual effect of tonification and purgation. It has been used to prevent and cure various diseases for more than 2000 years. Recent clinical and animal studies have testified that moxibustion therapy could alleviate the symptoms and/or pathology of PCOS.

In the clinical setting, moxibustion has been used to combine with oral herbal medicine (OHM) or WM in 
treating PCOS, especially in East Asia. Combination treatment of moxibustion is beneficial to enhance the therapeutic effect of infertility in PCOS. Both moxibustion plus OHM and moxibustion combined with OHM plus WM can get significantly a higher ovulation rate and pregnant rate than that of WM alone [167-170]. In a clinical trial, 187 infertility women with PCOS were randomized to receive CC, CC plus moxibustion, or CC plus HCG. Combination group of moxibustion had more dominant follicles compared to the CC group $(P<0.05)$ and achieves a similar effect of ovulation induction compared to the HCG group $(P>0.05)$ [171]. Findings implicated that moxibustion treatment can improve the therapeutic effects of conventional WMs including letrozole, clomiphene citrate, oral contraceptives, and metformin [167-169, 172]. With regard to the parameters of reproductive hormone, the combination group of moxibustion was associated with significantly lower levels of LH, FSH, and T $[169,170,173]$. Furthermore, adjuvant treatment of moxibustion offers advantages over WM alone in the improvement of efficacy and safety of drugs, significantly reducing the occurrence of luteinized unruptured follicle syndrome (LUFS) [171, 174]. Hence, moxibustion combined with OHM, which could normalize the sex hormones, may be useful for the PCOS women who plan to get pregnant. The therapeutic effect of moxibustion may be related with a series of physiological responses to heat stimulation generated by burning moxa from patients' and chemical stimulation from the pharmaceutical components of moxa [175]. Pharmacological research displays that the moxa, which is rich in flavonoids and polysaccharides, has strong antioxidant activity. Modern scientific research found that moxibustion exerted significantly anti-inflammatory effect, and it also can ameliorate the body immunity by regulating immune factors and immune cells [176-178]. Moxibustion on governor vessel can effectively adjust the biased state of constitution of people with yang deficiency constitution and observably elevates the levels of immunoglobulin M (IgM), immunoglobulin G ( $\operatorname{IgG})$, serum supple C3, and serum supple C4 [179, 180]. These are the potential mechanisms of moxibustion therapy.

\section{Summary}

At present, the majority of conventional western drugs contain single active ingredients which are active against a single biological target. However, because of the complexity of the human body, the western drug treatment might seem rather simplistic and limited for PCOS. And then, more and more women with PCOS turn to CAM to treat ovulatory and menstrual dysfunction, hormonal imbalance, insulin resistance, and other mental and psychological problems. Among the four kinds of complementary and alternative therapies for PCOS discussed in this review, herbal formula and single herbal are the most commonly used main therapies of PCOS. Moreover, there are combination therapies of acupuncture and herbal medicine, dietetic therapies, and moxibustion therapies which were used for the treatment of PCOS. All of these therapies of CAM can contribute to improve the symptoms of PCOS women in different degrees. A great deal of RCT data are available for HM; however, owing to the lack of blinding in most of the studies, it is likely that the results have a tendency to bias. High-quality designs are desperately needed to assess the efficacy of herbal medicine-associated CAM for PCOS. Additionally, novel and innovative therapies of CAM such as combinational methods are needed in treating PCOS. Importantly, herbal medicine-associated CAM therapy as a promising therapy for the patients with PCOS is worthy of further research in the near future.

\section{Conflicts of Interest}

The authors declare that there are no conflicts of interest in this work.

\section{Acknowledgments}

This work was supported by the Young Scientists Fund of the National Natural Science Foundation of China (81803945).

\section{References}

[1] A. E. Joham, H. J. Teede, S. Ranasinha, S. Zoungas, and J. Boyle, "Prevalence of infertility and use of fertility treatment in women with polycystic ovary syndrome: data from a large community-based cohort study," Journal of Women's Health, vol. 24, no. 4, pp. 299-307, 2015.

[2] H. J. Boyle, M. L. Misso, M. F. Costello et al., "Recommendations from the international evidence-based guideline for the assessment and management of polycystic ovary syndrome," Fertility and Sterility, vol. 110, no. 3, pp. 364-379, 2018.

[3] G. Norman, M. G. Massaro, A. Di Sabatino, V. Cappelli, and V. De Leo, "Therapeutic approach for metabolic disorders and infertility in women with PCOS," Gynecological Endocrinology, vol. 34, no. 1, pp. 4-9, 2018.

[4] D. A. Dumesic, S. E. Oberfield, E. Stener-Victorin, J. C. Marshall, J. S. Laven, and R. S. Legro, "Scientific statement on the diagnostic criteria, epidemiology, pathophysiology, and molecular genetics of polycystic ovary syndrome," Endocrine Reviews, vol. 36, no. 5, pp. 487-525, 2015.

[5] T. Legro, P. J. Hardiman, I. Petersen, and G. Baio, "Incidence and prevalence of diabetes and cost of illness analysis of polycystic ovary syndrome: a Bayesian modelling study," Human Reproduction, vol. 33, no. 7, pp. 1299-1306, 2018.

[6] E. Ernst, "Prevalence of use of complementary/alternative medicine: a systematic review," Bulletin of the World Health Organization, vol. 78, no. 2, pp. 252-257, 2000.

[7] Complementary, Alternative, or Integrative Health: What's in a Name?, National Center for Complementary and Integrative Health, Bethesda, MD, USA, 2016, https://nccih.nih. gov/health/integrativehealth.

[8] S. Arentz, C. A. Smith, J. A. Abbott, and A. Bensoussan, "A survey of the use of complementary medicine by a self-selected community group of Australian women with polycystic ovary syndrome," BMC Complementary \& Alternative Medicine, vol. 14, p. 472, 2014.

[9] S. Rooney and B. Pendry, "Phytotherapy for polycystic ovarian syndrome: a review of the literature and evaluation of practitioners' experiences," Journal of Herbal Medicine, vol. 4, no. 3, pp. 159-171, 2014. 
[10] Z. Mo, S. F. Li, and Y. D. Chen, "Effect of Bushen Quyu Huatan decoction on ovarian function and pregnancy outcome in patients with infertility caused by polycystic ovary syndrome," Chinese Archives of Traditional Chinese Medicine, vol. 37, no. 11, pp. 2768-2771, 2019.

[11] P. Luo, F. R. Tang, M. X. He, and C. R. Li, "Efficacy of Yangyinshugan capsule on ovarian hemodynamics and pregnancy outcomes in patients with polycystic ovarian syndrome complicated with infertility," Pharmacology and Clinics of Chinese Materia Medica, vol. 34, no. 2, pp. 109-112, 2018.

[12] X. L. Ru, F. Liu, J. Q. Liu, and Z. X. Du, "Kidney-supplementing blood-quickening liver-clearing formula combined with clomiphene for 90 cases of polycystic ovary syndrome," Journal of Traditional Chinese Medicine, vol. 54, no. 14, pp. 1214-1216, 2013.

[13] A. W. Wei, H. D. Z. Xiao, and Y. L. Song, "Clinical efficacy observation of Dingkun pills combined with clomiphene in the treatment of polycystic ovary syndrome with infertility," Chinese Journal of Practical Gynecology and Obstetrics, vol. 34, no. 4, pp. 444-447, 2018.

[14] Q. Yuan, C. Y. Xue, X. Wang, and W. Wei, "Clinical efficacy of Guizhu Yikun decoction combined with letrozole in the treatment of clomiphene-resistant polycystic ovary syndrome infertility," Chinese Archives of Traditional Chinese Medicine, pp. 1-6, 2019.

[15] R. N. Zhao, H. Yang, F. Chen, and S. Y. Li, "Clinical observation on therapy of strengthening spleen and tonifying kidney combined with clomiphene in improving the pregnancy rate of infertile patients with polycystic ovary syndrome," Academic Journal of Shanghai University of Traditional Chinese Medicine, vol. 33, no. 5, pp. 27-31, 2019.

[16] H. M. Wu, Z. P. Li, Y. Q. Wang, and L. J. Xiang, "Influence of Tiaojing decoction on quality of follicle and hormone secretion on polycystic ovary syndrome," Chinese Journal of Experimental Traditional Medical Formulae, vol. 20, no. 18, pp. 200-203, 2014.

[17] L. Lai, A. Flower, P. Prescott, and T. Wing, "Standardised versus individualised multiherb Chinese herbal medicine for oligomenorrhoea and amenorrhoea in polycystic ovary syndrome: a randomised feasibility and pilot study in the UK," BMJ Open, vol. 7, no. 2, Article ID E011709, 2017.

[18] X. F. Chen, Y. H. Wei, L. Lv, and J. L. Liu, "Clinical effects of Zuogui soothing liver decoction on polycystic ovary syndrome infertility," Chinese General Practice, vol. 20, no. 22, pp. 2796-2800, 2017.

[19] C. Y. Zhao, L. Wang, L. L. Yu, and X. Long, "Clinical discussion of PCOS combined with infertility treated by TCM promoting ovulation decoction combined with ethinylestradiol cyproterone and metformin," Maternal and Child Health Care of China, vol. 29, no. 19, pp. 3109-3112, 2014.

[20] F. Y. Zhao, H. F. Zhao, M. Ma, and Y. Xu, "Effects of qigong pills decoction combined with chemical drugs on serum hormone levels of polycystic ovarian syndrome patients complicated with infertility," China Pharmacy, vol. 28, no. 17, pp. 2416-2418, 2017.

[21] C. F. Ding, C. Y. Wang, X. Yang, and R. H. Zheng, "Effect of modified Cangfu daotan decoction in improving endometrial receptivity in infertility patients with polycystic ovarian syndrome," Chinese Journal of Integrated Traditional and Western Medicine, vol. 34, no. 11, pp. 1297-1301, 2014.

[22] C. X. Wang and Y. W. Li, "Bailing Tiaogan decoction in treating infertilitas feminis of liver qi stagnation type polycystic ovary syndrome," Chinese Journal of Experimental
Traditional Medical Formulae, vol. 22, no. 13, pp. 165-168, 2016.

[23] X. P. Li, S. Lin, S. Ye, and Y. S. Cai, "Therapeutic efficacy of modified Zigui decoction in treatmnent of polycystic ovary syndrome of Gan-shen Yin deficiency syndrome," Chinese Journal of Integrated Traditional and Western Medicine, vol. 31, no. 8, pp. 1070-1073, 2011.

[24] J. Zhai, Q. H. Jiang, Z. R. Tian, and L. Ou, "Efficacy of Jianpibushen recipe joint Metformin in endocrine and biochemical features of obese PCOS patients," China Journal of Traditional Chinese Medicine and Pharmacy, vol. 26, no. 11, pp. 2682-2684, 2011.

[25] T. Dong, "Clinical observation of Bushen Jianpi decoction in the treatment of polycystic ovary syndrome," Journal of Sichuan of Traditional Chinese Medicine, vol. 34, no. 1, pp. 88-89, 2016.

[26] M. Liu and H. L. Wang, "Clinical study on the treatment of kidney deficiency phlegm-dampness polycystic ovary syndrome with tonifying kidney and resolving phlegm prescription," Journal of Sichuan of Traditional Chinese Medicine, vol. 33, no. 3, pp. 71-74, 2015.

[27] X. J. Zhang, Y. Q. Chen, S. Q. Gui, and Q. H. Qian, "Clinical observation on Tiangui capsule for 110 cases of polycystic ovary syndrome," Journal of Traditional Chinese Medicine, vol. 55, no. 21, pp. 1835-1840, 2014.

[28] D. Meng, "Clinical observation on treatment of infertility with polycystic ovary syndrome by shugan Bushen decoction combined with letrozole and lts effect on serum progesterone," Chinese Archives of Traditional Chinese Medicine, vol. 36, no. 2, pp. 507-509, 2018.

[29] Y. Liu and L. H. Mao, "Effect of danzhi xiaoyao pill on ovulation induction of polycystic ovarian syndrome patients of pathogenic fire derived from stagnation of Gan-qi," Chinese Journal of Integrated Traditional and Western Medicine, vol. 33, no. 9, pp. 1191-1195, 2013.

[30] J. Li and F. Sun, "Clinical observation on Bushen Huoxue cupailuan decoction in the treatment of infertility induced by polycystic ovary syndrome of kidney deficiency and blood stasis," China Pharmacy, vol. 28, no. 20, pp. 2840-2842, 2017.

[31] X. Z. Zhou, Y. L. Liu, W. Yue, and Q. Wang, "Clinical effects of Bushen Huoxue Culuan Prescription in the treatment of kidney and blood stasis due to polycystic ovary syndrome," The Chinese Journal of Clinical Pharmacology, vol. 33, no. 9, pp. 786-789, 2017.

[32] J. Yu, L. Q. Liu, D. X. Zhai, and D. Y. Zhang, "The effects of Yushi Oinggan recipe in treating polycystic ovary syndrome with dampness-heat of Gan channel: a randomized controlled trial," Chinese Journal of Integrated Traditional and Western Medicine, vol. 39, no. 3, pp. 282-287, 2019.

[33] N. Zhang, "Effect of invigorating kidney and removing phlegm herbs on women with polycystic ovary syndrome undergoing in vitro fertilization and embryo transplantation treatment," Journal of Liaoning University of Traditional Chinese Medicine, vol. 13, no. 7, pp. 56-58, 2011.

[34] Y. Liang, Q. H. Tian, Y. X. Mu, and H. L. Du, "Effects of Cangfu congxian decoction on oxidative stress in polycystic ovary syndrome patients," Chinese Journal of Integrated Traditional and Western Medicine, vol. 36, no. 6, pp. 685689, 2016.

[35] F. Lian, Z. G. Sun, J. W. Zhang, and Y. L. Teng, "Combined therapy of Chinese medicine with in vitro fertilization and embryo transplantation for treatment of polycystic ovarian syndrome," Chinese Journal of Integrated Traditional and Western Medicine, vol. 11, pp. 977-980, 2008. 
[36] F. Lian and S. Zhao, "Effects of shen invigorating and chongchannel regulating method on anti-müllerian hormone and oocyte quality in polycystic ovarian syndrome patients," Chinese Journal of Integrated Traditional and Western Medicine, vol. 32, no. 1, pp. 9-12, 2012.

[37] F. Lian, S. Zhang, Z. G. Sun, and Y. Yu, "Effects of erzhi Tiangui and qigong compound on the AKT-GLUT4 insulin signal pathway of polycystic ovarian syndrome and IVF-et outcomes," Chinese Journal of Integrated Traditional and Western Medicine, vol. 38, no. 4, pp. 410-414, 2018.

[38] J. J. Zhu, H. J. Zhang, J. Y. Liu, and H. X. Sun, "Effect of compound Xuanju capsule on superovulation in patients with kidney-yang deficiency polycystic ovary syndrome," Jiangsu Medical Journal, vol. 39, no. 22, pp. 2769-2770, 2013.

[39] H. J. Ye, Y. J. Jiang, A. P. Li, and Y. Yu, "Clinical observation on treating polycystic ovary syndrome with sterility with Guizhifulin capsule and Diane-35 and clomifene citrate," Chinese Journal of Clinical Pharmacology and Therapeutics, vol. 17, no. 6, pp. 691-695, 2012.

[40] F. Lian, S. Tian, and X. Y. Zhang, "Effect of erzhi Tiaojing granules on follicle quality in infertility patients with polycystic ovary syndrome," Journal of Traditional Chinese Medicine, vol. 52, no. 2, pp. 114-117, 2011.

[41] L. Qian, Y. Lu, and Y. Zhang, "Tonifying kidney and removing blood stasis methods with western medicine ovulation drugs treatment on polycystic ovary syndrome," Chinese Archives of Traditional Chinese Medicine, vol. 33, no. 7, pp. 1750-1752, 2015.

[42] H. Y. Chen, L. Tang, C. C. Xiao, and J. Luo, "Effect of Chinese medicine cycle therapy combined with metformin on normal weight polycystic ovary syndrome and its effect on sex hormone and insulin resistance," China Medical Herald, vol. 15, no. 36, pp. 90-94, 2018.

[43] T. Zhang, "Effect of qingre Yangyin recipe on endocrine and metabolism of polycystic ovary syndrome patients," Chinese Journal of Integrated Traditional and Western Medicine, vol. 35, no. 10, pp. 1175-1180, 2015.

[44] Y. H. Li and G. Yuan, "Effect of self-made Tiaojing Decoction on polycystic ovary syndrome of type of kidney deficiency and phlegm-dampness and its influence on TCM symptoms, endocrine and glycolipid metabolism," Modern Journal of Integrated Traditional Chinese and Western Medicine, vol. 28, no. 17, pp. 1861-1865, 2019.

[45] P. Wang, H. Lin, Q. Huang, and Y. Yang, "Treatment of polycystic ovary syndrome (type of kidney deficiency and blood stasis) with Bushen Huoluo Fang," Journal of Beijing University of Traditional Chinese Medicine, vol. 36, no. 9, pp. 637-639+644, 2013.

[46] X. M. Liu, X. Xu, D. X. Zheng, and S. Wen, “Treatment of PCOS hyperandrogenism patients with yin deficiency induced fire hyperactivity syndrome by modified Zhibai Dihuang decoction," Chinese Journal of Integrated Traditional and Western Medicine, vol. 38, no. 1, pp. 29-32, 2018.

[47] Y. Y. Sun, S. P. Li, and Y. Tan, "Clinical study on sequential method of yin-nourishing and yang-tonifying prescription combined with western medicine for patients with hyperandrogenism in PCOS," Journal of New Chinese Medicine, vol. 52, no. 3, pp. 100-103, 2020.

[48] M. H. Ma and X. D. Wang, "The application of method regulating kidney and clearing lung in the treatment of 26 cases with hyperandro-genism caused by PCOS," Journal of Nanjing University of Traditional Chinese Medicine, vol. 26, no. 4, pp. 311-312, 2010.
[49] Q. Yin, L. H. Hou, Y. H. Liu, and J. Ge, "Clinical observation of "Bushen Huatan Recipe"for the treatment of polycystic ovary syndrome with hyperandrogenism," Shanghai Journal of Traditional Chinese Medicine, vol. 49, no. 8, pp. 53-55+70, 2015.

[50] Y. L. Liu, C. X. Song, H. L. Bao, and H. Y. Xu, "Dihuang wan combined with Xionggui erchen tang on hyperandrogenism and polycystic ovary syndrome with syndrome of kidney deficiency and blood stasis," Chinese Journal of Experimental Traditional Medical Formulae, vol. 24, no. 18, pp. 180-185, 2018.

[51] N. Ainehchi, A. Khaki, A. Farshbaf-Khalili, M. Hammadeh, and E. Ouladsahebmadarek, "The effectiveness of herbal mixture supplements with and without clomiphene citrate in comparison to clomiphene citrate on serum antioxidants and glycemic biomarkers in women with polycystic ovary syndrome willing to be pregnant: a randomized clinical trial," Biomolecules, vol. 9, no. 6, p. 215, 2019.

[52] S. Ouladsahebmadarek, C. A. Smith, J. Abbott, P. Fahey, B. S. Chemma, and A. Bensoussan, "Combined lifestyle and herbal medicine in overweight women with polycystic ovary syndrome (PCOS): a randomized controlled trial," Phytotherapy Research, vol. 31, no. 9, pp. 1330-1340, 2017.

[53] Y. H. Cheema, X. B. Li, and J. Xiao, "Clinical observation of Wenjing Shexue Fang in treating polycystic ovarian syndrome," Journal of Guangzhou University of Traditional Chinese Medicine, vol. 32, no. 3, pp. 418-422, 2015.

[54] W. F. Bao and M. L. Ying, "Clinical effects of modified Yunpi Huatan decoction on obese patients with polycystic ovary syndrome," China Journal of Traditional Chinese Medicine and Pharmacy, vol. 25, no. 5, pp. 768-770, 2010.

[55] R. N. Liang, Z. Liu, P. S. Li, and P. Fan, "Kuntai capsules improve glucolipid metabolism in patients with polycystic ovary syndrome: a randomized, double-blind, placebocontrolled trial," Medicine, vol. 98, no. 39, 2019.

[56] Y. Chen, L. Q. Ye, Y. Jiang, and Y. X. Song, "The combination of kidney-tonifying liver and blood-activating cycle regulating method and metformin can improve lipid metabolism in patients with polycystic ovary syndrome," Zhejiang Journal of Traditional Chinese Medicine, vol. 52, no. 9, pp. 668-669, 2017.

[57] F. Wei, Y. Qiu, and H. Y. He, "Clinical observation on qiangshen tablets combined with longlu capsules for 73 cases of polycystic ovary syndrome with insulin resistance," Journal of Traditional Chinese Medicine, vol. 55, no. 16, pp. 1386-1389, 2014.

[58] C. X. Lu, C. K. Fan, and L. H. Hou, "Clinical analysis of Bushen Huatan fang in the treatment of insulin resistance PCOS," Acta Chinese Medicine and Pharmacology, vol. 43, no. 6, pp. 58-61, 2015.

[59] W. J. Chen and F. F. Wang, "Effect of Quyu Huatan decoction on lipid metabolism and hormone levels of patients with polycystic ovary syndrome," China Journal of Chinese Materia Medica, vol. 41, no. 3, pp. 532-535, 2016.

[60] J. Wan, "Effect of Cangfu daotan decoction on hormone level and lipid metabolism in patients with obese polycystic ovary syndrome," Shaanxi Journal of Traditional Chinese Medicine, vol. 38, no. 2, pp. 219-221, 2017.

[61] X. M. Zhen, Z. J. Hua, and C. F. Ding, "Effects of Cangfu Daotan decoction on reproductive Endocrinology and glucose metabolism in patients with phlegm-dampness polycystic ovary syndrome complicated with insulin resistance," Zhejiang Journal of Integrated Traditional Chinese and Western Medicine, vol. 23, no. 3, pp. 216-217, 2013. 
[62] Y. H. Diao, H. Y. Yan, Y. Huang, and L. G. Yuan, “A clinical observation on treating polycystic ovary syndrome with insulin resistance and obesity patients by integrated Chinese and western medicine," Chinese Journal of Basic Medicine in Traditional Chinese Medicine, vol. 23, no. 8, pp. 1170-1173, 2017.

[63] Y. Deng, W. Xue, Y.-f. Wang et al., "Insulin resistance in polycystic ovary syndrome improved by Chinese medicine Dingkun pill: a randomized controlled clinical trial," Chinese Journal of Integrative Medicine, vol. 25, no. 4, pp. 246-251, 2019.

[64] H. F. Zhu, Q. M. Du, and C. P. Huang, "Bailing capsules combined with metformin has effect on metabolism indexes and sex hormone of polycystic ovary syndrome," Journal of New Chinese Medicine, vol. 50, no. 12, pp. 137-139, 2018.

[65] Q. Wang, J. B. Yu, and J. N. Li, "Clinical observation of Jianpi Huatan prescription combined with western medicine for obesity PCOS," Journal of New Chinese Medicine, vol. 49, no. 4, pp. 78-80, 2017.

[66] X. Sun, C. F. Ding, X. Yang, and X. R. Zhan, "Effects of Bushen Tiaogan recipe on glucolipid metabolism in nonobese patients with polycystic ovary syndrome," Chinese Journal of Integrated Traditional and Western Medicine, vol. 37, no. 5, pp. 530-533, 2017.

[67] X. B. Li, J. L. Zhai, L. Y. Li, and X. D. Hu, "Influence of lingzhu granules on endocrine and lipid metabolism of polycystic ovary syndrome patients," Journal of Traditional Chinese Medicine, vol. 52, no. 1, pp. 31-34, 2011.

[68] F. Lian, M. Qi, and Y. Li, "The effect of PCOS on the expression of endogenous secretion, metabolism and serum Apelin in patients with IR," Hunan Journal of Traditional Chinese Medicine, vol. 30, no. 10, pp. 1-5+103, 2014.

[69] Y. L. Li, X. Y. Ruan, Y. Zhao, and J. Du, "Effects of Bailing capsules on metabolism in patients with polycystic ovary syndrome," Journal of Capital Medical University, vol. 37, no. 4 , pp. 437-443, 2016.

[70] L. Hua, Y. N. Wu, J. M. Zhang, and S. Y. Chai, "Clinical study of Yishen Jianpi Yangxue Tongli therapy in treating polycystic ovary syndrome," Chinese Journal of Integrated Traditional and Western Medicine, vol. 11, pp. 819-822, 2003.

[71] R. Ma, X. M. Wang, and X. L. Zhu, "Clinical efficacy of Bushen Tiaochong decoction in obesity patients with polycystic ovary syndrome and effect on endometrial receptivity," Chinese Journal of Experimental Traditional Medical Formulae, vol. 24, no. 5, pp. 188-192, 2018.

[72] X. C. Zhang, "Effect observation and mechanism research of Tiaojing Huoxue decoction in treating polycystic ovary syndrome," Jiangxi Journal of Traditional Chinese Medicine, vol. 48, no. 1, pp. 31-33, 2017.

[73] Q. Cao, J. Yu, and L. R. Zhou, "Clinical observation of "Kuntai Formula" for the treatment of polycystic ovary syndrome," Shanghai Journal of Traditional Chinese Medicine, vol. 48, no. 6, pp. 66-69, 2014.

[74] Y. L. Teng, R. Yu, Z. H. Xu, and J. X. Pan, "The effect of YiShenJianPi decoction on dyslipidemia in women with polycystic ovary syndrome undergoing frozen embryo transfer," Journal of Wenzhou Medical University, vol. 49, no. 6, pp. 418-422, 2019.

[75] Y. Wang, "Clinical observation on 45 cases of polycystic ovarian syndrome accompanied with emotional disturbance treated by shugan Tiaojing formula," Journal of Traditional Chinese Medicine, vol. 52, no. 17, pp. 1479-1482, 2011.

[76] L. Tian and C. X. Wang, "Ovulation induction curative effect of Dan Zhi xiaoyao pill in the auxiliary treatment of polycystic ovary syndrome patients with depression of the liver generated pathogenic fire," The Chinese Journal of Human Sexuality, vol. 25, no. 5, pp. 107-109, 2016.

[77] J. Fu, G. L. Zhu, and N. M. Wang, "Study on the curative effect of Kaiyu Erchen decoction and Guizhi Fuling wan in treating Infertility caused by mutual knot of phlegm and blood stasis," Shanxi Journal of Traditional Chinese Medicine, vol. 40, no. 3, pp. 341-343, 2019.

[78] L.-h. Wang, X. Wang, X.-z. Yu, and W.-t. Xu, "Potent therapeutic effects of Shouwu Jiangqi decoction on polycystic ovary syndrome with insulin resistance in rats," Chinese Journal of Integrative Medicine, vol. 22, no. 2, pp. 116-123, 2016.

[79] W. T. Xu, M. Y. Tang, J. H. Wang, and L. H. Wang, "Identification of the active constituents and significant pathways of Cangfu daotan decoction for the treatment of PCOS based on network pharmacology," Evidence-Based Complementary and Alternative Medicine, vol. 2020, Article ID 4086864, 2020.

[80] Z. Qiu, J. Dong, C. Xue et al., "Liuwei Dihuang Pills alleviate the polycystic ovary syndrome with improved insulin sensitivity through PI3K/Akt signaling pathway," Journal of Ethnopharmacology, vol. 250, Article ID 111965, 2020.

[81] H. X. Liu, D. C. Zhou, Y. Chen, and D. L. Liu, "Beneficial effects of Heqi san on rat model of polycystic ovary syndrome through the PI3K/AKT pathway," Daru: Journal of Faculty of Pharmacy, vol. 25, no. 1, p. 21, 2017.

[82] J. B. Xu, X. Y. Wang, F. Ji, and L. S. Huang, "Effect of Tanzhixiao recipe on PI3K/akt pathway in PCOS-IR model rat," Chinese Journal of Experimental Traditional Medical Formulae, vol. 22, no. 24, pp. 156-160, 2016.

[83] R. Bai, W. H. Chen, S. L. Li, and C. Shi, "Effect of tonifying kidney and activating blood and resolving toxing and turbid method and metformin on GLP-1, GLP-2 and PYY in patients with obesity-induced polycystic ovary syndrome," Liaoning Journal of Traditional Chinese Medicine, vol. 46, no. 3, pp. 546-549, 2019.

[84] M. Jamilian, F. Foroozanfard, E. Kavossian et al., "Effects of curcumin on body weight, glycemic control and serum lipids in women with polycystic ovary syndrome: a randomized, double-blind, placebo-controlled trial," Clinical Nutrition ESPEN, vol. 36, pp. 128-133, 2020.

[85] B. H. Shafabakhsh, M. Q. Li, C. L. Chen, and Y. J. Luo, "Effects of TCM periodic therapy on sex hormone, glucose and lipid metabolism of patients with polycystic ovary syndrome," Chinese Journal of Information on Traditional Chinese Medicine, vol. 23, no. 1, pp. 35-38, 2016.

[86] C. Zhang, X. J. Xu, Y. H. Huang, and Y. J. Li, "Study on the mechanism of tonifying kidney and resolving phlegm method regulating glucose and lipid metabolism of obese PCOS female mice through APN signal pathway," Lishizhen Medicine and Materia Medica Research, vol. 29, no. 5, pp. 1025-1028, 2018.

[87] F. Ding, J. Zhou, and X. F. Yi, "Study on the relationship between serum leptin, adiponectin, resistin and polycystic ovary syndrome," Chinese Journal of Clinical Research, vol. 32, no. 8, pp. 1087-1090, 2019.

[88] Q. Zeng, H. X. Zhang, and Y. N. Wang, "Effect of Bushen Huatan Huoxue method on endometrial tolerance in patients with PCOS ovulation infertility," Journal of Sichuan of Traditional Chinese Medicine, vol. 35, no. 8, pp. 136-139, 2017.

[89] X. Y. Li, Q. Yang, and Q. Wang, "Effects of Cangfu daotan decoction combined with clomiphene on serum hormone 
level and endometri-al Receptivity in patients with polycystic ovary syndrome combined with infertility," China Pharmacy, vol. 28, no. 26, pp. 3698-3701, 2017.

[90] J. Du, "Effect of Bushen Tiaojing decoction in promoting ovulation among polycystic ovarian syndrome Barrenness patients," Chinese Journal of Experimental Traditional Medical Formulae, vol. 21, no. 16, pp. 171-174, 2015.

[91] X. M. Tian, Y. H. Huang, X. J. Xu, and M. Zhang, "Study on mechanism of VEGF/akt pathway regulating endometrial receptivity of obese PCOS female rats by kidney-nourishing and phlegm-removing method," Chinese Archives of Traditional Chinese Medicine, vol. 38, no. 7, pp. 169-172, 2020.

[92] L. L. Zhang, Z. G. Han, and R. Yang, "Effects of qigong pills formula on uterine artery blood flow and endometrial receptivity of patients with polycystic ovary syndrome with infertility," China Pharmacy, vol. 28, no. 35, pp. 4967-4970, 2017.

[93] X. L. Tong, Y. Tan, Y. Y. Yin, and G. Zhou, "Sequential therapy combined with ovulation induction of PCOS in endometrium of infertile women," Chinese Traditional Patent Medicine, vol. 39, no. 12, pp. 2491-2496, 2017.

[94] Z. W. Wang, J. Zheng, C. F. Xu, and X. L. Cheng, "Effects of Turongbushen prescription on endometrial receptivity of polycystic ovarian syndrome in rats," Immunological Journal, vol. 29, no. 12, pp. 1052-1056, 2013.

[95] X. Chen, "Study about influence mechanism of Tiangui decoction on intensifying insulin resistance and improving sex hormone in PCOS rats," Chinese Archives of Traditional Chinese Medicine, vol. 33, no. 3, pp. 682-684, 2015.

[96] H. Yang, Y. H. Lee, S. R. Lee, P. Kaya, E.-J. Hong, and H. W. Lee, "Traditional medicine (Mahuang-Tang) improves ovarian dysfunction and the regulation of steroidogenic genes in letrozole-induced PCOS rats," Journal of Ethnopharmacology, vol. 248, Article ID 112300, 2020.

[97] H. Hong, Q. Huang, P. Wang, and Y. Yang, "Influences of Bushen Huoluo Fang on sex hormones and ovarian morphology in rats with polycystic ovary syndrome," Journal of Beijing University of Traditional Chinese Medicine, vol. 37, no. 5, pp. 330-332+343+365, 2014.

[98] X. Chen, "Effect of removing blood stasis and phlegm method to the comprehensive sex hormone and ovarian morphology in rats with polycystic ovary syndrome," Journal of Basic Chinese Medicine, vol. 21, no. 12, pp. 1514-1515+1529, 2015.

[99] B. J. Zhang, Y. H. Feng, L. Zhang, and H. F. Xia, "Influence of Bushen Cupai formula on the expression of luteinizing hormone receptor and follicle stimulating hormone receptor in rat ovarian granulosa cells," Modern Journal of Integrated Traditional Chinese and Western Medicine, vol. 26, no. 8, pp. 807-809+850, 2017.

[100] H. Chang, H. Y. Kuang, J. Cong, and C. Liang, "Effects of Bushen Huatan compound particle on reproduction endocrinology of PNA rats' female offspring," China Journal of Traditional Chinese Medicine and Pharmacy, vol. 26, no. 12, pp. 2872-2875, 2011.

[101] Y. H. Guo, Y. Tan, and Y. J. Zou, "Effects of Bushen cupailuan decotion on granular cell aromatase in polycystic ovary syndrome model rats," Journal of Nanjing University of Traditional Chinese Medicine, vol. 32, no. 1, pp. 38-40, 2016.

[102] Q. Chen, Y. S. Sun, X. Sun, and B. Zhang, "Effect of Yishen Tiaogan III recipe on the expression of luteinizing hormone receptor in ovary of rats with polycystic ovary syndrome," Journal of Traditional Chinese Medicine, vol. 52, no. 16, pp. 1409-1412, 2011.
[103] Y. Liu, F. Q. Xing, L. H. Zhang, and L. L. Jing, "Effects of Dan Zhi Xiao-Yao Power on rat polycystic ovary syndrome and its regulation of P450arom and ERK 1/2," Journal of Jinan University( Medicine Edition), vol. 33, no. 2, pp. 144-147, 2012.

[104] M. Liu, Y. Liu, Y. Tan, and Y. Wang, "Effect of Qinghuayure recipe on proliferation, secretion and related gene expression of rat ovarian membrane cells," Journal of Nanjing University of Traditional Chinese Medicine, vol. 29, no. 2, pp. 141-145, 2013.

[105] N. Lan, S. Wang, W. P. Qiu, and R. Chen, "Effects of compound malt pill on the expression of IL-6, TNF- $\alpha$ in PCOS model rats," Pharmacology and Clinics of Chinese Materia Medical, vol. 32, no. 3, pp. 136-140, 2016.

[106] H. Y. Sun, Q. Li, Y. Y. Liu, and X. H. Wei, "Xiao-yao-san, a Chinese medicine formula, ameliorates chronic unpredictable mild stress induced polycystic ovary in rat," Frontiers in Physiology, vol. 8, p. 729, 2017.

[107] A. Swaroop, A. S. Jaipuriar, S. K. Gupta et al., "Efficacy of a novel fenugreek seed extract (Trigonella foenum-graecum, FurocystTM) in polycystic ovary syndrome (PCOS)," International Journal of Medical Sciences, vol. 12, no. 10, pp. 825-831, 2015.

[108] L. X. Kumar, Y. Z. Kong, Y. W. Ren, and M. Shen, "Therapeutic effect of berberine combined with diformin for women with polycystic ovary syndrome and insulin resistance," Journal of Zhejiang Chinese Medical University, vol. 35, no. 5, pp. 713-715, 2011.

[109] H. H. Kamel, "Role of phyto-oestrogens in ovulation induction in women with polycystic ovarian syndrome," $E u$ ropean Journal of Obstetrics \& Gynecology and Reproductive Biology, vol. 168, no. 1, pp. 60-63, 2013.

[110] A. Y. Shahin and S. A. Mohammed, "Adding the phytoestrogen Cimicifugae Racemosae to clomiphene induction cycles with timed intercourse in polycystic ovary syndrome improves cycle outcomes and pregnancy rates-a randomized trial," Gynecological Endocrinology, vol. 30, no. 7, pp. 505-510, 2014.

[111] M. H. Bashtian, S. A. Emami, N. Mousavifar, and H. A. Esmaily, "Evaluation of fenugreek (Trigonella foenum-graceum L.), effects seeds extract on insulin resistance in women with polycystic ovarian syndrome," Iranian Journal Pharmaceutical Research, vol. 12, no. 2, pp. 475-481, 2013.

[112] M. M. Wang, H. Y. Xue, and J. X. Zhong, "Effect of tanshinone pretreatment combined with ovulation induction on pregnancy outcome of polycystic ovary syndrome patients with metabolic disorders," Chinese Journal of Clinical Research, vol. 29, no. 11, pp. 1479-1481, 2016.

[113] N. M. Wang, Y. F. Yang, H. X. Wang, and Y. C. Yang, "Clinical research of menshi Xiaonang Yin combined with tanshinone capsules in the treatment of kidney deficiency and phlegm stasis type polycystic ovary syndrome," Lishizhen Medicine and Materia Medica Research, vol. 29, no. 9, pp. 2200-2203, 2018.

[114] X. B. Li, H. Kuang, Y. Y. Luo, and Q. X. Chen, "Clinical observation of berberine in intervening insulin resistance of polycystic ovary syndrome," Journal of Guangzhou University of Traditional Chinese Medicine, vol. 34, no. 2, pp. 172-177, 2017.

[115] M. B. Li, J. S. Gao, L. H. Kou, and C. Liu, "Regulation effect of berberine on hormones levels in polycystic ovary syndrome women with insulin resistance," Maternal and Child Health Care of China, vol. 30, no. 11, pp. 1718-1720, 2015. 
[116] Y. An, Z. Sun, Y. Zhang, B. Liu, Y. Guan, and M. Lu, "The use of berberine for women with polycystic ovary syndrome undergoing IVF treatment," Clinical Endocrinology, vol. 80, no. 3, pp. 425-431, 2014.

[117] X. K. Guan, Y. Y. Wang, J. P. Liu, and R. N. Liang, "Randomized controlled trial of letrozole, berberine, or a combination for infertility in the polycystic ovary syndrome," Fertility and Sterility, vol. 106, no. 3, pp. 757-765, 2016.

[118] D. H. Kort and R. A. Lobo, "Preliminary evidence that cinnamon improves menstrual cyclicity in women with polycystic ovary syndrome: a randomized controlled trial," American Journal of Obstetrics \& Gynecology, vol. 211, no. 5, p. 487, 2014.

[119] S. A. Naeimi, M. Tansaz, F. Sohrabvand, and H. Hajimehdipoor, "Assessing the effect of processed nigella sativa on oligomenorrhea and amenorrhea in patients with polycystic ovarian syndrome: a pilot study," International Journal of Pharmaceutcis, vol. 9, no. 11, pp. 4716-4722, 2018.

[120] A. M. Jazani, H. Nazemiyeh, M. Tansaz, and H. S. Bazargani, "Celery plus Anise versus metformin for the treatment of oligomenorrhea in the polycystic ovary syndrome: a tripleblind randomized clinical trial: Tabriz University of Medical Sciences," Iranian Red Crescent Medical Journal, vol. 20, no. 5, 2018.

[121] M. Jamilian and Z. Asemi, "The effects of soy isoflavones on metabolic status of patients with polycystic ovary syndrome," The Journal of Clinical Endocrinology \& Metabolism, vol. 101, no. 9, pp. 3386-3394, 2016.

[122] P. Ghahremaninasab, M. Shahnazi, A. F. Khalili, and K. Hamdi, "The effects of combined low-dose oral contraceptives and Vitex agnus on the improvement of clinical and paraclinical parameters of polycystic ovarian syndrome: a triple-blind randomized controlled clinical trial," Iranian Red Crescent Medical Journal, vol. 18, no. 12, 2016.

[123] M. Shahnazi, A. F. Khalili, S. P. Beilankouh, and F. Sadrimehr, "Effects of second and third generation oral contraceptives on lipid and carbohydrate metabolism in overweight and obese women: a randomized triple-blind controlled trial," Iranian Red Crescent Medical Journal, vol. 18, no. 9, 2016.

[124] S. Sohaei, R. Amani, M. J. Tarrahi, and H. Ghasemi-Tehrani, "The effects of curcumin supplementation on glycemic status, lipid profile and hs-CRP levels in overweight/obese women with polycystic ovary syndrome: a randomized, double-blind, placebo-controlled clinical trial," Complementary Therapies in Medicine, vol. 47, Article ID 102201, 2019.

[125] J. Heshmati, F. Golab, M. Morvaridzadeh et al., "The effects of curcumin supplementation on oxidative stress, Sirtuin-1 and peroxisome proliferator activated receptor $\gamma$ coactivator $1 \alpha$ gene expression in polycystic ovarian syndrome (PCOS) patients: a randomized placebo-controlled clinical trial," Diabetes \& Metabolic Syndrome: Clinical Research \& Reviews, vol. 14, no. 2, pp. 77-82, 2020.

[126] J. Akbari-Fakhrabadi, H. Y. Xue, X. Q. Fan, and Y. Q. Cheng, "Effect of tanshinone on glucose metabolism in patients with polycystic ovary syndrome," Medical Journal of National Defending Forces in Northwest China, vol. 36, no. 9, pp. 610-612, 2015.

[127] J. Y. Zhang, H. Y. Xue, J. Su, and Y. H. Zuo, "Clinical effects of tanshinone on polycystic ovary syndrome patients with hyperandrogenism," Guangxi Medical Journal, vol. 37, no. 6, pp. 767-769, 2015.
[128] M. M. Wu, N. Liu, and L. Han, "Effect of Tanshinone capsule on lipid metabolism and hypothalamus-pituitary-adrenal axis in patients with polycystic ovary syndrome," Shandong Medical Journal, vol. 56, no. 32, pp. 94-96, 2016.

[129] R. M. Li, "Efficacy of Tanshinone capsule combined with ethinylestradiol cyproterone in the treatment of 43 patients with polycystic ovary syndrome in childbearing age," Ningxia Medical Journal, vol. 41, no. 2, pp. 172-173, 2019.

[130] L. Amini, F. Mojab, S. Jahanfar, M. Sepidarkish, Z. Raoofi, and A. Maleki-Hajiagha, "Efficacy of Salvia officinalis extract on the prevention of insulin resistance in euglycemic patients with polycystic ovary syndrome: a double-blinded placebocontrolled clinical trial," Complementary Therapies in Medicine, vol. 48, Article ID 102245, 2020.

[131] W. J. Raoofi, H. B. Hu, S. F. Zhu, and J. Liu, “Anti-oxidative stress effect of puerarin in the course of the treatment for obese polycystic ovary syndrome," Maternal and Child Health Care of China, vol. 32, no. 17, pp. 4111-4116, 2017.

[132] A. A. Khan and W. Begum, "Efficacy of Darchini in the management of polycystic ovarian syndrome: a randomized clinical study," Journal of Herbal Medicine, vol. 15, Article ID 100249, 2019.

[133] M. Hajimonfarednejad, M. Nimrouzi, M. Heydari, M. M. Zarshenas, M. J. Raee, and B. N. Jahromi, "Insulin resistance improvement by cinnamon powder in polycystic ovary syndrome: a randomized double-blind placebo controlled clinical trial," Phytotherapy Research, vol. 32, no. 2, pp. 276-283, 2018.

[134] A. Raee, M. Rafraf, and M. Asghari-Jafarabadi, "Cinnamon improves metabolic factors without detectable effects on adiponectin in women with polycystic ovary syndrome," Asia Pacific Journal of Clinical Nutrition, vol. 27, no. 3, pp. 556-563, 2018.

[135] W. Wuttke, H. Jarry, and D. Seidlová-Wuttke, "Cimicifuga racemosa extract for the treatment of climacteric complaints," Journal of Endocrinology and Reproduction, vol. 10, no. 2, pp. 106-110, 2006.

[136] J. G. Wang, R. A. Anderson, G. M. Graham et al., "The effect of cinnamon extract on insulin resistance parameters in polycystic ovary syndrome: a pilot study," Fertility and Sterility, vol. 88, no. 1, pp. 240-243, 2007.

[137] Y.-L. Sauer, A. M. Dunning, M. Dowsett et al., "Phytoestrogen exposure is associated with circulating sex hormone levels in postmenopausal women and interact with ESR1 and NR1I2 gene variants," Cancer Epidemiology Biomarkers \& Prevention, vol. 16, no. 5, pp. 1009-1016, 2007.

[138] B. Roemheld-Hamm, "Chasteberry," American Family Physician, vol. 72, no. 5, pp. 821-824, 2005.

[139] B. Qin, M. Nagasaki, M. Ren, G. Bajotto, Y. Oshida, and Y. Sato, "Cinnamon extract (traditional herb) potentiates in vivo insulin-regulated glucose utilization via enhancing insulin signaling in rats," Diabetes Research and Clinical Practice, vol. 62, no. 3, pp. 139-148, 2003.

[140] A.-L. Oshida, G.-H. Li, Y.-R. Li et al., "Lignan and flavonoid support the prevention of cinnamon against oxidative stress related diseases," Phytomedicine, vol. 53, pp. 143-153, 2019.

[141] H. Ren, D. J. Graves, and R. A. Anderson, "Cinnamon extract regulates glucose transporter and insulin-signaling gene expression in mouse adipocytes," Phytomedicine, vol. 17, no. 13, pp. 1027-1032, 2010.

[142] S. H. Jung, J. H. Han, H. S. Park, and D. H. Lee, "Effects of unaltered and bioconverted mulberry leaf extracts on cellular glucose uptake and antidiabetic action in animals," $B M C$ 
Complementary and Alternative Medicine, vol. 19, no. 1, p. 55, 2019.

[143] P. Anand, K. Y. Murali, V. Tandon, P. S. Murthy, and R. Chandra, "Insulinotropic effect of cinnamaldehyde on transcriptional regulation of pyruvate kinase, phosphoenolpyruvate carboxykinase, and GLUT4 translocation in experimental diabetic rats," Chemico-Biological Interactions, vol. 186, no. 1, pp. 72-81, 2010.

[144] Y. Chandra, Z. J. Lin, A. Z. Nie, and L. Y. Li, "Effect of Chinese herb chicory extract on expression of renal transporter Glut9 in rats with hyperuricemia," China Journal of Chinese Materia Medica, vol. 42, no. 5, pp. 958-963, 2017.

[145] R. Z. Zhang, "Clinical study of Bushen Huoxue decoction combined with abdominal acupuncture in treating oligomenorrhea in women with polycystic ovary syndrome," Electronic Journal Of Practical Gynecologic Endocrinology, vol. 6, no. 31, p. 98+104, 2019.

[146] L. Lin, "Clinical study of acupuncture combined with Chinese herbal medicine on improving ovulation function after laparoscopy in patients with polycystic ovary syndrome," Yunnan Journal of Traditional Chinese Medicine and Materia Medica, vol. 41, no. 1, pp. 52-55, 2020.

[147] Y. Yin, Y. C. Zhang, H. Zhang, and D. S. Jiang, "Clinical therapeutic effects of acupuncture combined with Chinese herbal medicine on infertility of polycystic ovary syndrome in the patients with ovulation induction with letrozole," Chinese Acupuncture \& Moxibustion, vol. 38, no. 1, pp. 2732, 2018

[148] L. Yu, Y. Liao, H. Wu et al., "Effects of electroacupuncture and Chinese kidney-nourishing medicine on polycystic ovary syndrome in obese patients," Journal of Traditional Chinese Medicine, vol. 33, no. 3, pp. 287-293, 2013.

[149] J. Wu, J. Bai, and R. H. You, "Effects of acupuncture combined with Chinese medcine on leptin and insulin resistance in obese patients with polycystic ovary syndrome," Journal of Sichuan of Traditional Chinese Medicine, vol. 32, no. 1, pp. 86-88, 2014.

[150] Y. Shi, Y. J. Liao, L. Q. Yu, and J. M. Zhao, "Clinical observation on acupancture combined with Chinese medication for 33 patient of polycystic ovary syndrome with obesity," Journal of Traditional Chinese Medicine, vol. 53, no. 22, pp. 1930-1933, 2012.

[151] L. Mannerås, I. H. Jonsdottir, A. Holmäng, and M. Lönn, E. Stener-Victorin, Low-frequency electro-acupuncture and physical exercise improve metabolic disturbances and modulate gene expression in adipose tissue in rats with dihydrotestosterone-induced polycystic ovary syndrome," Endocrinology, vol. 149, no. 7, pp. 3559-3568, 2008.

[152] L. Manneras, S. Cajander, M. Lonn, and E. Stener-Victorin, "Acupuncture and exercise restore adipose tissue expression of sympathetic markers and improve ovarian morphology in rats with dihydrotestosterone-induced PCOS," American Journal of Physiology-Regulatory, Integrative and Comparative Physiology, vol. 296, no. 4, pp. 1124-1131, 2009.

[153] L. Mannerås, S. Cajander, A. Holmäng et al., "A new rat model exhibiting both ovarian and metabolic characteristics of polycystic ovary syndrome," Endocrinology, vol. 148, no. 8, pp. 3781-3791, 2007.

[154] R. J. Stener-Victorin, J. Zhou, J. Q. Fang, and D. H. Yang, "Combination of acupuncture and Chinese medicinal herbs in treating model rats with polycystic ovary syndrome," African Journal of Traditional Complementary and Alternative Medicines, vol. 8, no. 4, pp. 353-361, 2011.
[155] P. Zou, "Traditional Chinese medicine, food therapy, and hypertension control: a narrative review of Chinese literature," The American Journal of Chinese Medicine, vol. 44, no. 8, pp. 1579-1594, 2016.

[156] Y. L. Liu, X. Z. Zhou, W. Yue, and L. J. Xiang, "Clinical observation on the treatment of kidney deficiency syndrome of polycystic ovary syndrome by meal nourishing decoction combined with letrozole," The Journal of Practical Medicine, vol. 33, no. 14, pp. 2393-2396, 2017.

[157] L. N. Liu, X. Chu, and J. Q. Li, "Clinical observation of dialectical combination of diet and acupoint catgut in the treatment of polycystic ovary syndrome kidney deficiency and liver depression," World Latest Medicine Information, vol. 19, no. 32, pp. 160-161, 2019.

[158] P. Zeng, J. Li, Y. Chen, and L. Zhang, "The structures and biological functions of polysaccharides from traditional Chinese herbs," Progress in Molecular Biology and Translational Science, vol. 163, pp. 423-444, 2019.

[159] H. G. Tehrani, M. Allahdadian, F. Zarre, and H. Ranjbar, "Effect of green tea on metabolic and hormonal aspect of polycystic ovarian syndrome in overweight and obese women suffering from polycystic ovarian syndrome: a clinical trial," Journal of Education and Health Promotion, vol. 6, p. 36, 2017.

[160] M. Farhadian, S. Barati, M. Mahmoodi, and A. B. Mosleh, "Comparison of green tea and metformin effects on anthropometric indicators in women with polycystic ovarian syndrome: a clinical trial study," Journal of Reports in Pharmaceutical Sciences, vol. 9, no. 1, pp. 97-103, 2020.

[161] E. Mombaini, S. Jafarirad, D. Husain, M. H. Haghighizadeh, and P. Padfar, "The impact of green tea supplementation on anthropometric indices and inflammatory cytokines in women with polycystic ovary syndrome," Phytotherapy Research, vol. 31, no. 5, pp. 747-754, 2017.

[162] P. Padfar, "Spearmint herbal tea has significant anti-androgen effects in polycystic ovarian syndrome. a randomized controlled trial," Phytotherapy Research, vol. 24, no. 2, pp. 186-188, 2010.

[163] I. Haj-Husein, S. Tukan, and F. Alkazaleh, "The effect of marjoram (Origanum majorana) tea on the hormonal profile of women with polycystic ovary syndrome: a randomised controlled pilot study," Journal of Human Nutrition and Dietetics, vol. 29, no. 1, pp. 105-111, 2016.

[164] C. C. W. Chan, M. W. L. Koo, E. H. Y. Ng, O.-S. Tang, W. S. B. Yeung, and P.-C. Ho, "Effects of Chinese green tea on weight, and hormonal and biochemical profiles in obese patients with polycystic ovary syndrome-a randomized placebo-controlled trial," Journal of the Society for Gynecologic Investigation, vol. 13, no. 1, pp. 63-68, 2006.

[165] H. Yeung, M. Azarnia, M. Nabiuni, and L. Karimzadeh, "The effect of green tea extract on reproductive improvement in estradiol valerate-induced polycystic ovary polycystic Ovarin syndrome in rat," Iranian Journal of Pharmaceutical Research, vol. 14, no. 4, pp. 1215-1233, 2015.

[166] M. Ghowsi, N. Yousofvand, and S. Moradi, "Effects of Salvia officinalis L. (common sage) leaves tea on insulin resistance, lipid profile, and oxidative stress in rats with polycystic ovary: an experimental study," Avicenna Journal of Phytomedicine, vol. 10, no. 3, pp. 263-272, 2020.

[167] L. L. Kang, Y. X. Li, and H. X. Zhou, "Syndrome differentiation combining moxibustion in the treatment of polycystic ovary syndrome infertility for 43 cases," Chinese Medicine Modern Distance Education of China, vol. 13, no. 5, pp. 61-62, 2015. 
[168] K. Li, K. Gao, Y. X. Ma, and Y. P. Yu, “Comparison of clinical treatment for promoting ovulation of polycystic ovary syndrome(PCOS) by herb-partitioned moxibustion and clomiphene," Journal of Clinical Acupuncture and Moxibustion, vol. 32, no. 8, pp. 50-52, 2016.

[169] Z. F. Liu and H. Q. Chen, "Effect of self-made Wenshen Jianpi fang combined with Acupoint moxibustion on Infertility patients with polycystic ovary syndrome of spleenkidney yang deficiency," Women's Health Research, vol. 1, pp. 153-154, 2017.

[170] L. J. Zhu, J. L. Hu, and S. F. Xiao, "The clinical observation of cang fu daotan decoction combined with acupoint heatsensitive moxibustion on infertility caused by phlegmdampness internal Obstruction polycystic ovary syndrome," Journal of Jiangxi University of Traditional Chinese Medicine, vol. 31, no. 5, pp. 58-60, 2019.

[171] Y. R. Chen, "Clinical study of moxibustion on uterine point in ovulation induction of polycystic ovary syndrome," China Practical Medicine, vol. 12, no. 13, pp. 117-118, 2017.

[172] C. Z. Bai, "Effect of Bushen Huoxue herb combined with moxibustion on sex hormone levels in patients with polycystic ovary syndrome," Cardiovascular Disease Electronic Journal of Integrated Traditional Chinese and Western Medicine, vol. 8, no. 16, p. 140, 2020.

[173] Q. N. Li and F. Yuan, "Clinical observation of self-made Yiqi Huoxue decoction combined with heat-sensitive moxibustion in the treatment of polycystic ovary syndrome," Guangming Journal of Chinese Medicine, vol. 34, no. 21, pp. 3287-3289, 2019.

[174] B. L. Li, H. Xie, and W. X. Ma, "Prevention of unruptured follicular luteinization syndrome by traditional Chinese medicine combined with moxibustion and western medicine: a report of 30 cases," Traditional Chinese Medicinal Research, vol. 27, no. 9, pp. 59-61, 2014.

[175] L. Wang, J. J. Lu, C. Z. Gu, and Y. H. Cheng, "Microwave method for the determination of the total content of volatile oil in the different seasons mugwort leaf," Journal of Mathematical Medicine, vol. 4, no. 3, p. 287, 2001.

[176] J. Xu, L.-j. Pan, and C.-s. Jia, "Exploration on the feasibility of moxibustion in prevention and treatment of COVID-19 from the perspective of modern medical mechanism," World Journal of Acupuncture-Moxibustion, vol. 30, no. 2, pp. 8184, 2020.

[177] M. Zhang, J. H. Li, L. Xiao, and Z. Q. Wang, "The effect of moxibustion Shenque point on immune function of digestive tract cancer patients undergoing chemotherapy," Contemporary Medical Symposium, vol. 16, no. 8, pp. 98-100, 2018.

[178] J. X. Xie, F. Cheng, Q. Peng, and Y. X. Xiang, "Effect of solarterm moxibustion on Hemorheology and immune function in patients with subhealth status of yang deficiency," Research of Integrated Traditional Chinese and Western Medicine, vol. 12, no. 1, pp. 1-4, 2020.

[179] Y. Zhao, T. G. Li, R. Pu, and L. Shui, "Effect of moxibustion on body weight and peripheral and cerebral cortical IL- 6 and IL-10 levels in fatigue rats," Acupuncture Research, vol. 45, no. 3, pp. 215-219, 2020.

[180] X. Liu, "Clinical study on the effect of du-moxibustion therapy on the symptom and levels of serum supplement C3 and C4 in yang-deficiency subjects," Guangming Journal of Chinese Medicine, vol. 33, no. 18, pp. 2725-2728, 2018. 